\title{
The Possible Ameliorative Effect of Mesenchymal Stem Cells and Curcumin Onbleomycin Induced Lung Injuries in the Adult Male Rats: Histological and Immunohistochemical Study
}

\section{Zeinab MAltaib ${ }^{1}$, Aisha EMansy ${ }^{2}$, Abeer M EIMahlawy ${ }^{2}$ and Dina Sabry ${ }^{*}$}

${ }^{1}$ Department of Histology and Cell Biology, Helwan Faculty of Medicine, Helwan University, Egypt

${ }^{2}$ Department of Histology and Cell Biology, Benha Faculty of Medicine, Benha University, Egypt

${ }^{3}$ Department of Medical Biochemistry and Molecular Biology, Faculty of Medicine, Cairo University, Cairo, Egypt

\begin{abstract}
Background: Bleomycin (BLM) is a chemotherapeutic agent that produces pulmonary fibrosis. Curcumin is a naturally occurring compound, uses in medicine and has many beneficial therapeutic effects. Bone Marrow Mesenchymal Stem Cells (BMSCs) is a novel approach with great therapeutic potential for the treatment of fatal pulmonary fibrosis.
\end{abstract}

Aim of the work: To evaluate whether or not curcumin improves the stem cells therapeutic effects on bleomycin induced lung injuries in adult male rats.

Material and methods: Fifty adult male rats were included and divided equally into 5 groups. Group I (control), Group II (bleomycin group): The rats received single intratracheal instillation of $1 \mathrm{mg} / \mathrm{kg}$ of bleomycin, Group III (curcumin group): The rats received curcumin $200 \mathrm{mg} / \mathrm{kg}$ body weight orally by gastric tube 5 days/week for 4 weeks, Group IV (stem cell group): The rats injected intraperitoneal by a single dose $3 \times 10^{6}$ of MSCs after 4 weeks of bleomycin injection, Group V (stem cell and curcumin group): The rats received curcumin as in the groups III after 4 weeks of bleomycin injection for 4 weeks and injected with the MSCs intraperitoneal after the last dose of curcumin. Lung samples were processed and examined using histological and immunohistochemical techniques.

Results: Group II showed thickening of interalveolar septa by RBCs and mononuclear cellular infiltration. Many collapsed alveoli, while other alveoli were dilated and ruptured. Their bronchiole lined by epithelial cells with deeply stained nuclei and their lumen were full of exfoliated epithelial cells. A significant increase in collagen and elastic fibers accumulation, positive PCNA immunoreactivity within the nuclei of cells lining alveoli and marked positive COX2 immunoreactivity within cytoplasmic of alveolar epithelial cells and in the bronchiolar epithelium. Group III, IV showed attenuation of some histological changes as compared to group II, while Group V showed improvement of the histological and immunohistochemical changes described before.

Conclusion: Bone marrow derived mesenchymal can attenuate bleomycin induced lung injuries in rats, but curcumin can yield better beneficial effect over the BMSCs therapy alone.

Keywords: Bleomycin; BMSCs; COX2; Curcumin; PCNA

\section{Introduction}

Pulmonary fibrosis is a chronic interstitial lung disease of unknown etiology. It can be idiopathic or developed as a complication of many respiratory and systemic diseases. It is the most common form of interstitial pneumonia and affects over five million people worldwide. This progressive lung disease has a poor prognosis and end to complete loss of lung function and death of the patient [1-3].

It is clinically characterized by lung volume reduction, restlessness, dyspnea, gas exchange impairment and a histological lesions in the form of excessive accumulation of Extracellular Matrix (ECM), fibroblast proliferation and remodeling of the lung architecture, followed by clinical symptoms, physiological disorders and radiographic findings $[4,5]$.

There are different models for inducing the experimental pulmonary fibrosis. Bleomycin is the most widely used experimental model of lung fibrosis, because the pathology in rats is very similar to human. In the current study, pulmonary fibrosis is induced in rats by intratracheal bleomycin (BLM) instillation [6].

Bleomycin is a chemotherapeutic antibiotic, produced by the bacterium "Streptomyces verticillus". It has strong antitumor activity and used mainly in treatment of Hodgkin, non-Hodgkin lymphomas, testicular carcinoma and malignant pleural effusion [7].
Although research trials are ongoing, there is no approved that any medication can significantly help in treatment of pulmonary fibrosis [1].

Curcumin (CR), (diferuloylmethane) yellow-orange dye extracted from the Indian spice turmeric. It is a low-molecular-weight polyphenol compound whose safety, tolerability, and lack of toxicity at high dose have been well established in both rodent and human studies [8]. It has a wide range of pharmacological and physiological actions such as antioxidant, scavenging free radicals, anti-inflammatory, antitumor, antimicrobial antiproliferative, proapoptotic and anti-atherosclerotic effects. It can decrease fibrosis level in liver, kidney, and lung of laboratory animal $[2,9]$.

${ }^{*}$ Corresponding authors: Dina Sabry, Professor of Medical Biochemistry and Molecular Biology, Faculty of Medicine, Cairo University, Cairo, Egypt, Tel: 01111200200; E-mail: Dinasabry@kasralainy.edu.eg

Received March 03, 2017; Accepted May 22, 2017; Published May 29, 2017

Citation: MAltaib Z, EMansy A, EIMahlawy AM, Sabry D (2017) The Possible Ameliorative Effect of Mesenchymal Stem Cells and Curcumin Onbleomycin Induced Lung Injuries in the Adult Male Rats: Histological and Immunohistochemical Study. J Stem Cell Res Ther 7: 389. doi: 10.4172/2157-7633.1000389

Copyright: @ 2017 MAltaib Z, et al. This is an open-access article distributed unde the terms of the Creative Commons Attribution License, which permits unrestricted use, distribution, and reproduction in any medium, provided the original author and source are credited. 
Citation: MAltaib Z, EMansy A, EIMahlawy AM, Sabry D (2017) The Possible Ameliorative Effect of Mesenchymal Stem Cells and Curcumin Onbleomycin Induced Lung Injuries in the Adult Male Rats: Histological and Immunohistochemical Study. J Stem Cell Res Ther 7: 389. doi: 10.4172/2157-7633.1000389

Page 2 of 13

Bone marrow derived stem cells (MSCs) are the novel promising approach for future therapies in repairing or regeneration of many tissues and also in tissue engineering, because they are easy to harvest, can be readily expanded in culture and differentiate into a number of cell types as osteoblasts, chondrocytes, astrocytes, pneumocytes, hepatocytes, neurons, and cardiac myocytesafter the induction of certain microenvironments and cellular factors in vitro or in vivo $[10,11]$.

MSCs are self-renewing, clonal precursors of nonhematopoietictissues and are found in various types of tissues and organs such as bone marrow, fat, muscles, lungs, liver, pancreas, and synovial membrane $[12,13]$. The present study was conducted as an effort to evaluate whether or not curcumin improves the stem cells' therapeutic effects on bleomycin induced lung injuries in adult male rats.

\section{Materials and Methods}

In this study, 50 adult male rats of average weight $150-250 \mathrm{~g}$ were used.

Animals were housed in the laboratory animal house unit of Kasr Al-Ainy Faculty of Medicine, Cairo University. Strict care and cleaning measures were utilized to keep the animal in a normal healthy state, the animals were housed in animal cages at room temperature $\left(25 \pm 1^{\circ} \mathrm{C}\right)$, relative humidity $(55 \pm 5)$ with $12 \mathrm{~h}$ light/12 h dark cycle, fed standard balanced diet and water ad-libitum. All ethical protocols for animal treatment were followed and were supervised by the animal facilities. The experimental protocol was approved by the Institutional Animal Care Committee.

\section{Used drugs}

Bleomycin sulfate (Merck Millipore, MA, United States) was purchased from Noor Scientific \& Trade (8 El Noor St, Shoubra El Khaema, Kaliobyea, Egypt). Bleomycin (BLM) dissolved in sterile (phosphate buffer saline) PBS $[14,15]$.

Curcumin was purchased from Sigma Company (Cat No. C7727; St Louis, Missouri, USA), it is bright yellow to orange color powder, insoluble in water but soluble in other solvents such corn oil. Curcumin was dissolved in corn oil as a vehicle [16].

Mesenchymal Stem Cell (MSCs) prepared from rat bone marrow (obtained from the stem cell research unit at the Biochemistry department of the Faculty of Medicine, Cairo University (Cairo, Egypt). Ten rats were used to prepare the MSCs. Isolation and culture of MSCs was carried out according to the method described by Soleimani and Nadri [17] with some modifications. All cultures were examined using an inverted microscope (Leica DM IL LED with camera Leica DFC295; Leica Microsystems CMS GmbH, Wetzlar, Germany).

\section{Experimental design}

Rats were divided into 5 groups included 10 rats for each.

Group I (control group): The animals of this group were further subdivided into 2 subgroups each one included 5 rats.

Subgroup IA: Rats were injected with intratracheal injection of PBS as a vehicle for 4 weeks. They were sacrificed at the same time as the corresponding experimental groups.

Subgroup IB: Rats received corn oil as a vehicle orally by gastric tube daily for 4 weeks. They were sacrificed at the same time as the corresponding experimental groups.

Group II (bleomycin group): Rats injected with a single intratracheal instillation of $1 \mathrm{mg} / \mathrm{kg}$ of bleomycin dissolved in PBS as a vehicle [1].

Group III (curcumin group): Rats received curcumin $200 \mathrm{mg} / \mathrm{kg}$ body weight dissolved in corn oil as a vehicle orally by gastric tube 5 days/week for 4 weeks after 4 weeks of bleomycin injection [16].

Group IV (stem cell group): Rats injected intraperitoneal by a single dose $3 \times 10^{6}$ of MSCs suspended in $0.5 \mathrm{ml}$ PBS after 4 weeks of bleomycin injection [18].

Group V (stem cell and curcumin group): Rats received curcumin as in the groups III after 4 weeks of bleomycin injection for 4 weeks and after the last dose of curcumin the animals were injected with the MSCs intraperitoneal.

At the end of the experiment, the rats were anaesthetized by inhalation of ether then, were sacrificed and the lung was exposed and excised. The lung biopsies were divided and fixed immediately in 10\% neutral buffered formalin. Paraffin sections were prepared and stained with hematoxylin and eosin ( $\mathrm{H}$ and $\mathrm{E}$ ) to verify histological details and Masson's trichrome to assess sub-epithelial collagen deposition and orcein stain to assess elastic fibers to assess [19].

\section{Immunohistochemistry study}

1. Imunohistochemical staining for detection of antiproliferating cell nuclear antigen (PCNA); the primary monoclonal antibody used was anti-PCNA IgG antibody (Santa Cruz Biotechnology Inc., Santa Cruz, CA, USA). The cellular site of the reaction was nuclear and brown color.

2. Imunohistochemical staining for detection of Cox-2 antibody: Cox-2 is responsible for the biosynthesis of prostaglandins under acute inflammatory conditions [20]. Rabbit anti-mouse polyclonal antibody (Catalog number 160106; IHC World, Life Science, Ellicott City, USA), diluted 1:500 with IHC-Tek antibody diluent (Catalog number IW1001), and was used.

Imunohistochemical study was conducted using the avidin-biotin peroxidase method. Briefly, sections of about $5 \mu \mathrm{m}$ were deparaffinized, rehydrated, rinsed in tap water, and embedded in $3 \% \mathrm{H}_{2} \mathrm{O}_{2}$ for $10 \mathrm{~min}$ to block endogenous peroxidase.

The sections were treated initially with $2 \%$ trypsin at $37^{\circ} \mathrm{C}$ for $10 \mathrm{~min}$ in order to increase the sensitivity of the immunoperoxidase staining method. Sections were immersed in an antigen retrieval solution (10 $\mathrm{mmol} / \mathrm{l}$ sodium citrate buffer, $\mathrm{pH}$ 6) and subjected to heat-induced antigen retrieval for $20 \mathrm{~min}$ in a microwave. Nonspecific protein binding was blocked by a blocking solution (Phosphate Buffer Solution (PBS) and $10 \%$ normal goat serum). The slides were incubated for $30 \mathrm{~min}$ with the diluted primary antibody using PBS. Drops of streptavidin peroxidase were added to the slide, left for $20 \mathrm{~min}$ and then washed with PBS for 5 min. Diaminobenzidine (Dakopatts, Glostrup, Denmark) was added to slides as a chromogen, after which the slides were washed with distilled water. Finally, the sections were counterstained with hematoxylin, dehydrated, rendered transparent with xylene, mounted and observed under a light microscope. For the negative control the specific primary antibody was replaced by phosphate-buffered saline.

\section{Tracking of Intraperitoneal Stem Cells}

MSCs labelled with Green Fluorescent Protein (GFP) were observed in lung cryosections using Fluorescence Microscope (Leica Microsystems CMS GmbH). 
Citation: MAltaib Z, EMansy A, EIMahlawy AM, Sabry D (2017) The Possible Ameliorative Effect of Mesenchymal Stem Cells and Curcumin Onbleomycin Induced Lung Injuries in the Adult Male Rats: Histological and Immunohistochemical Study. J Stem Cell Res Ther 7: 389 . doi: 10.4172/2157-7633.1000389

Page 3 of 13

\section{Biochemical measurements}

Homogenate preparation: Portions of lung tissues were homogenized in a saline solution $(0.9 \%)$, centrifuged at $3000 \mathrm{rpm}$ for 15 min, and the supernatant was stored at $-20^{\circ} \mathrm{C}$ until they were analyzed.

1. Malondialdehyde (MDA): It is the breakdown product of lipid peroxidation and was analyzed according to the method by Valenzuela, $1991[21]$.

2. Reduced glutathione (GSH): Reduced glutathoine (GSH) was determined spectrophotomertically using glutathione reductase and 5.5' dithiobid (2-nitrobenzoic acid) as described by Grifith, 1980 [22].

3. Tumor necrosis factor $\alpha$ (TNF- $\alpha$ ): Quantitive determination of serum (TNF- $\alpha$ ) a lung proinflammatory cytokine was carried by using a commercially available enzyme-linked immunosorbent assay (Genzyme Immunobiologicals, Cambridge, U.K.) following the protocol provided by manufacturer. Results were expressed as nanograms per milliliter of tissue protein ( $\mathrm{ng} / \mathrm{ml})$ [23].

Morphometric analysis: Using a Leica Qwin 500 image analysis computer system (Leica Microsystems Ltd, Cambridge, UK) at the Pathology department, Faculty of Medicine, Cairo University the following parameters were measured: From each fifth serial section, 10 nonoverlapping fields were measured. The following measures were recorded:

1. Mean area\% of collagen fiber content was measured in the Masson's trichrome-stained sections at a magnification of $\times 400$ for each specimen using the color detect menu. The image analyzer was used to measure the area of collagen fiber content and was expressed in an area in relation to a standard measuring frame. This was done in 10 microscopic fields for each rat and their mean was obtained.

2. Mean area\% of elastic fiber content was measured in the Orcien-stained sections at a magnification of $\times 100$ for each specimen using the color detect menu. The image analyzer was used to measure the area of elastic fiber content and was expressed in an area in relation to a standard measuring frame. This was done in 10 microscopic fields for each rat and their mean was obtained.

3. Mean area\% of positive immunoreactivity for PCNA measured in 10 high-power fields for each specimen at a magnification of $\times 400$. They were measured using the color detect menu and in relation to a standard measuring frame.

4. Mean area\% of Cox-2 immunoreaction was determined in 10 high-power fields for each specimen at a magnification of $\times 400$. They were measured using the color detect menu and in relation to a standard measuring frame.

Statistical analysis was carried out using IBM SPSS statistics software for Windows, Version 20 (IBM Corp., Armonk, NY, USA) [24].

\section{Histological results}

Bone marrow mesenchymal stem cell characterization: On the 14 days of isolation and culture of ratbone marrow mesenchymal stem cell appeared the attached cells form colonies. These cells are spindle shaped with some polyhedral cells in between the colonies (Figure 1). In Figure 2A showed labeling of MSCs with Green Fluorescent Protein (GFP), (in vitro). Figure 2B shows homing of the injected labeled mesenchymal stem cells by detecting Green Fluorescent Protein (GFP) in the rat lung (in vivo).

\section{Haematoxylin and eosin}

Group I (control group): The section of the control rat showed normal histological architecture of the lung. They appeared to be formed of thin inter-alveolar septa, together with bronchi, bronchioles, alveolar ducts, alveoli, alveolar sacs and blood vessels. The bronchiole appeared to be lined with simple columnar ciliated epithelium and surrounded by concentric layers of smooth muscle fibers (Figures 3 and 4).

Group II (bleomycin group): This group showed various histological changes such as its bronchiole lined by epithelial cells with deeply stained nuclei and its lumen was full of exfoliated epithelial cells. Heavy mononuclear cellular infiltration surrounding the bronchioles and in the interalveolar septa. The thickening of interalveolar septa by RBCs and mononuclear cellular infiltration (Figure 5). Many collapsed alveoli, while other alveoli are dilated and ruptured. Heavy mononuclear cellular infiltration surrounding the bronchioles and in the interalveolar septa. The extravasated RBCs were present in the alveolar spaces. The dilated and congested blood vessels and interstitial hemorrhage in the alveolar spaces were seen (Figures 6 and 7).

Group III (curcumin and bleomycin group): This group showed many collapsed alveoli, while other alveoli are dilated and ruptured. Few mononuclear cellular infiltration surrounding the bronchioles and in the interalveolar septa, the extravasated red blood cells and congested blood vessels were seen (Figure 8).

Group IV (stem cell and bleomycin group): This group showed some collapsed alveoli, while other alveoli are dilated and ruptured. Few mononuclear cellular infiltration surrounding the bronchioles and in the interalveolar septa were seen (Figure 9).

Group V (curcumin, stem cell and bleomycin group): This group showed many alveoli of variable size, alveolar ducts. Some thickened interalveolar septa were seen studded with mononuclear cellular infiltration, whereas others were apparently thin (Figure 10).

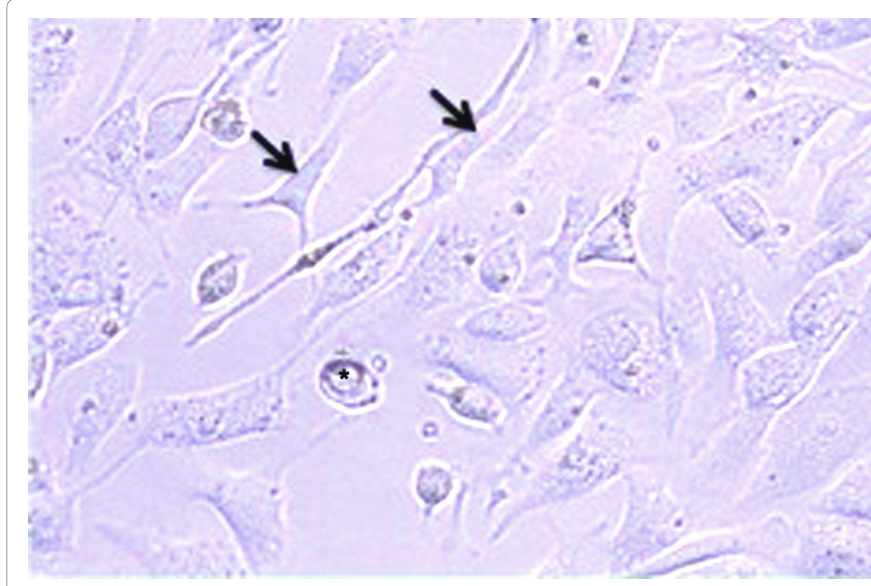

Figure 1: Inverted microscope micrograph of a primary culture of bone marrow-derived mesenchymal stem cells on day 14 of isolation and culture. The attached cells form colonies. These cells are spindle shaped $(\uparrow)$ with some polyhedral cells $\left(^{*}\right)$ in between the colonies (X1000). 
Citation: MAltaib Z, EMansy A, EIMahlawy AM, Sabry D (2017) The Possible Ameliorative Effect of Mesenchymal Stem Cells and Curcumin Onbleomycin Induced Lung Injuries in the Adult Male Rats: Histological and Immunohistochemical Study. J Stem Cell Res Ther 7: 389. doi: 10.4172/2157-7633.1000389
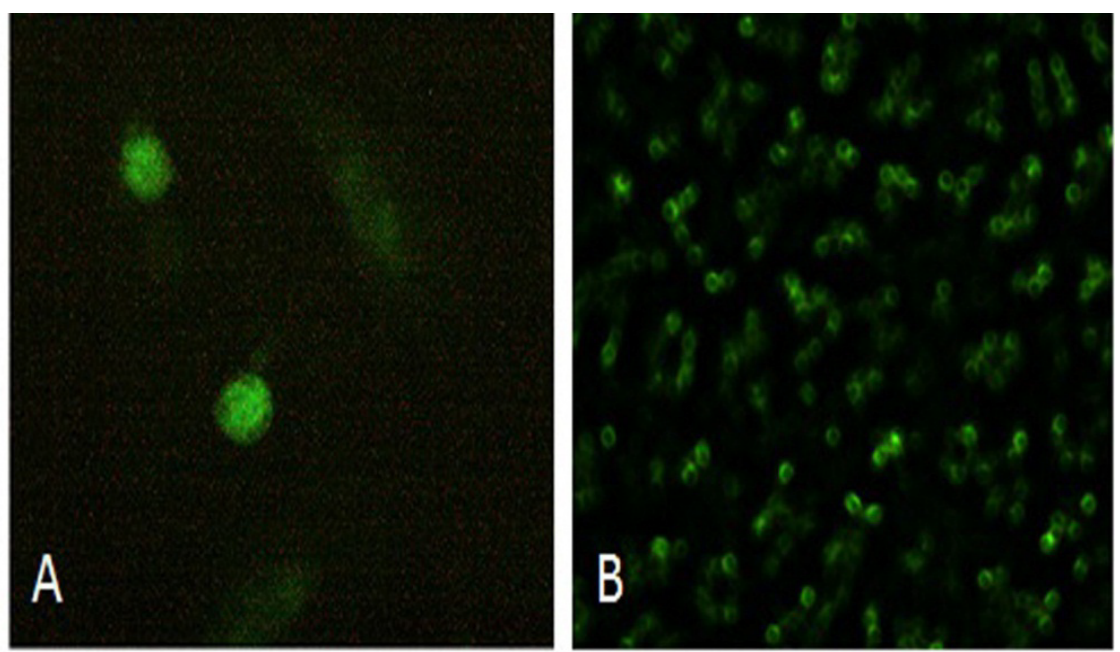

Figure 2: Fluorescent microscope micrograph (A) Labeling of MSCs with GFP fluorescent protein (in vitro) (GFPX1000). (B) Homing of the injected labeled mesenchymal stem cells by detecting GFP in the rat lung (in vivo) (GFPX500).

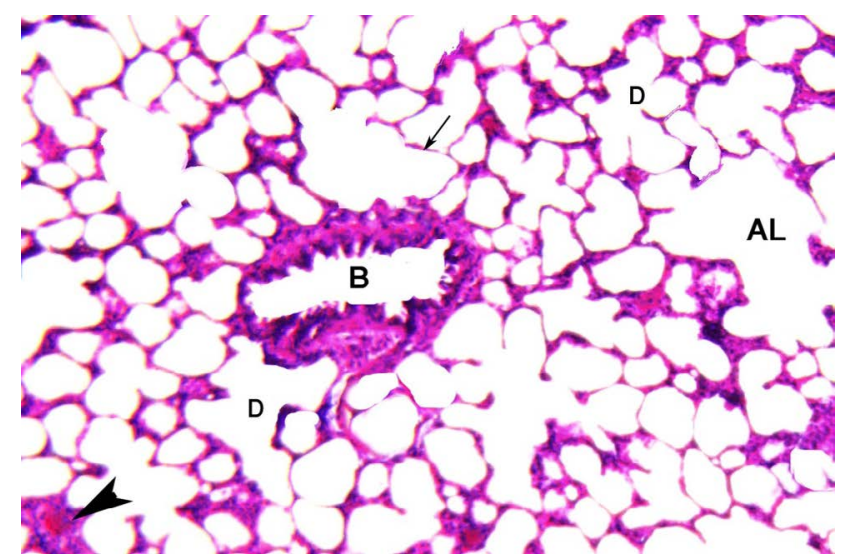

Figure 3: A photomicrograph of a section in rat lung of Group I (control group) showing many alveoli (AL), alveolar ducts (D), bronchioles (B), blood vessels (arrow head $\boldsymbol{\Delta}$ ) and thinner interalveolar septa (arrow $\uparrow)(H$ and $E, X 200)$.

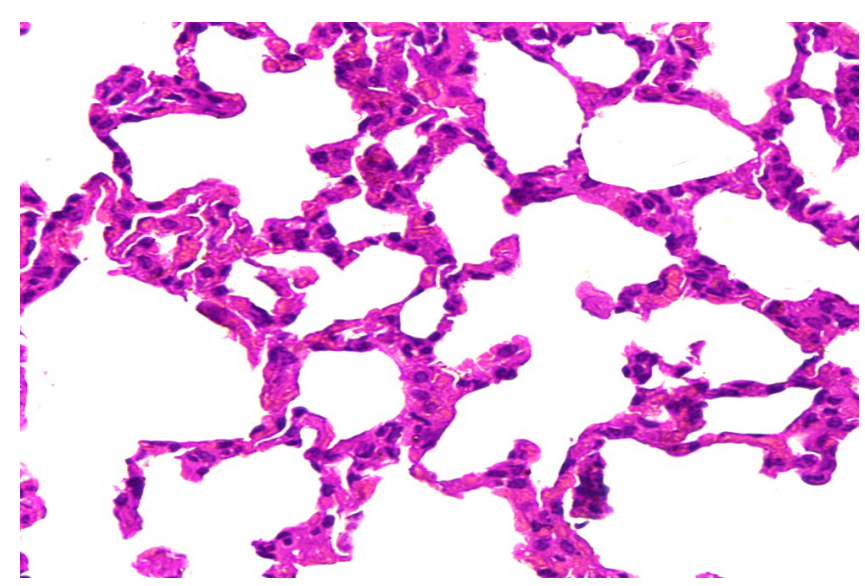

Figure 4: A photomicrograph of a section in rat lung of Group I showing many alveoli $(A L)$, alveolar ducts $(D)$, and thinner interalveolar septa (arrow $\uparrow)(H$ and $\mathrm{E}, \mathrm{X} 400)$.

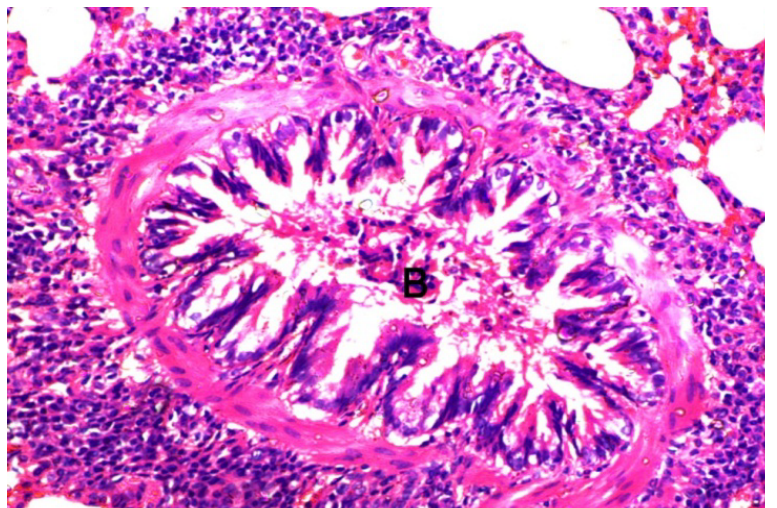

Figure 5: A photomicrograph of a section in rat lung of Group II showing bronchiole (B) lined by epithelial cells with deeply stained nuclei and its lumen is full of exfoliated epithelial cells. Heavy mononuclear cellular infiltration (I) surrounding the bronchioles and in the interalveolar septa. Notice the thickening of interalveolar septa by RBCs andmononuclear cellular infiltration (arrow $\uparrow)(\mathrm{H}$ and $\mathrm{E}, \mathrm{X} 400)$

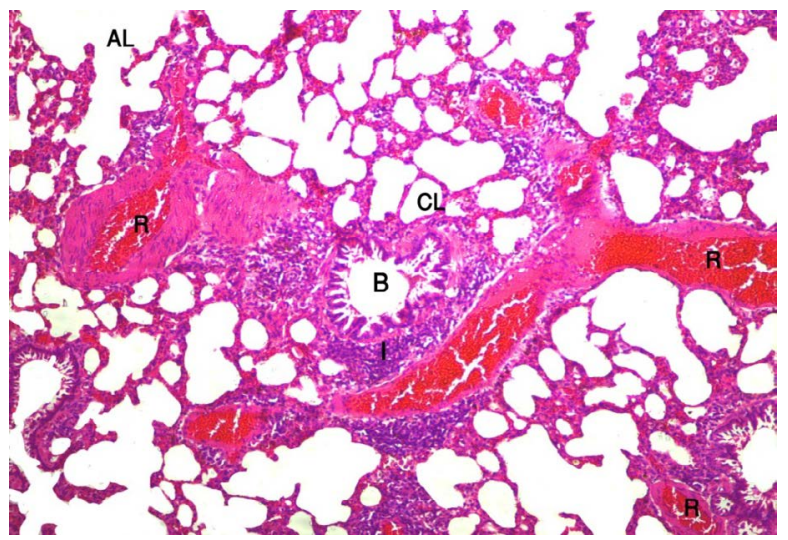

Figure 6: A photomicrograph of a section in rat lung of Group II showing many collapsed alveoli $(C L)$, while other alveoli are dilated and ruptured (AL). Heavy mononuclear cellular infiltration (I) surrounding the bronchioles (B) and in the interalveolar septa. Notice extravasated RBCs (R) in the alveolar spaces and dilated and congested blood vessel ( $H$ and $E, X 200)$. 
Citation: MAltaib Z, EMansy A, EIMahlawy AM, Sabry D (2017) The Possible Ameliorative Effect of Mesenchymal Stem Cells and Curcumin Onbleomycin Induced Lung Injuries in the Adult Male Rats: Histological and Immunohistochemical Study. J Stem Cell Res Ther 7: 389. doi: 10.4172/2157-7633.1000389

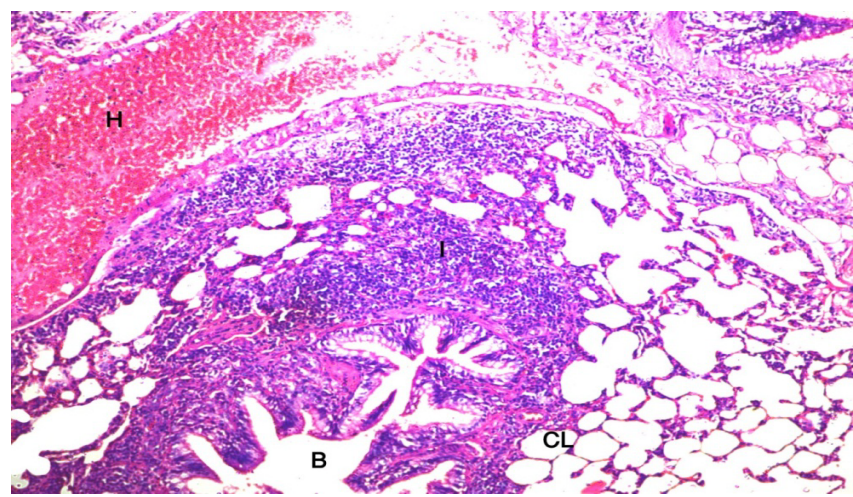

Figure 7: A photomicrograph of a section in rat lung of Group II showing many collapsed alveoli (CL), Heavy mononuclear cellular infiltration (I) surrounding the bronchioles (B) and in the interalveolar septa. Notice interstitial hemorrhage $(\mathrm{H})$ in the alveolar spaces $(\mathrm{H}$ and $\mathrm{E}, \mathrm{X} 200)$.

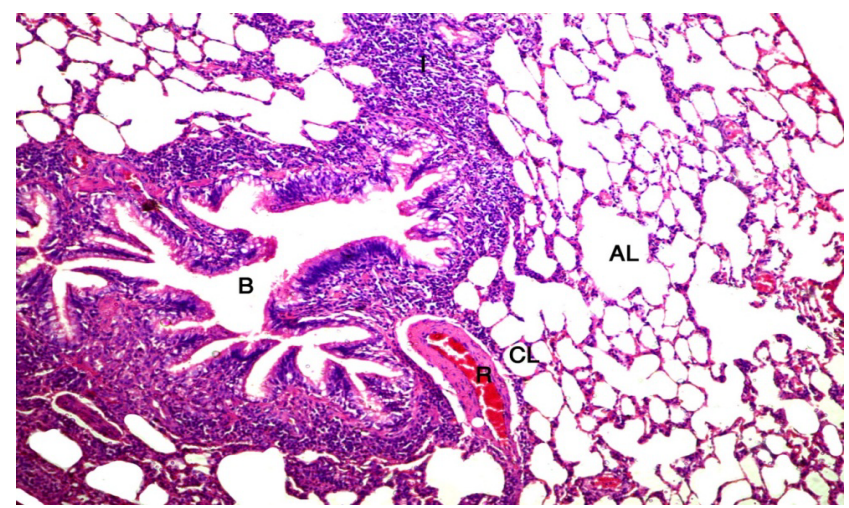

Figure 8: A photomicrograph of a section in rat lung of Group III showing many collapsed alveoli $(\mathrm{CL})$, while other alveoli are dilated and ruptured (AL). Notice few mononuclear cellular infiltration (B) surrounding the bronchioles (B) and in the interalveolar septa. Extravasated red blood cells $(\mathrm{R})$ and congested blood vessels are seen ( $H$ and $E, X 200)$.

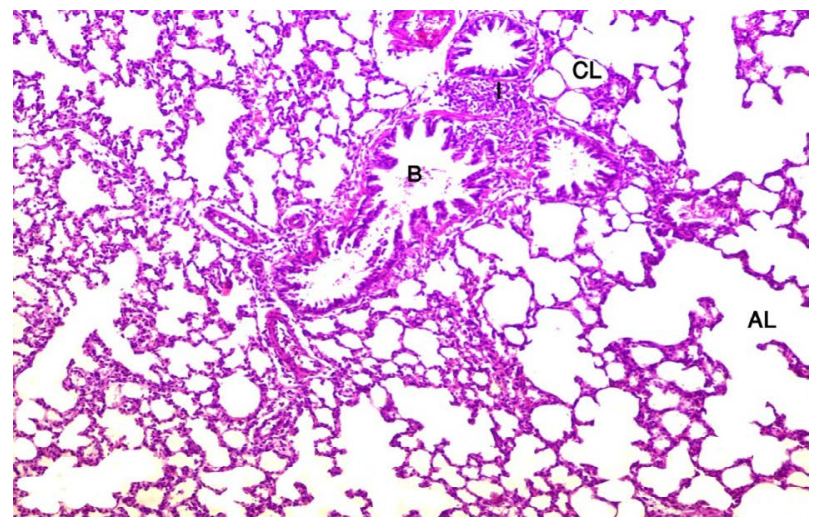

Figure 9: A photomicrograph of a section in rat lung of Group IV showing some collapsed alveoli $(C L)$, while other alveoli are dilated and ruptured $(A L)$. Notice few mononuclear cellular infiltration (I) surrounding the bronchioles and in the interalveolar septa ( $\mathrm{H}$ and $\mathrm{E}, \mathrm{X} 200)$.

\section{Masson's trichrome stain}

Group I (control group): Sections of control rat revealed the

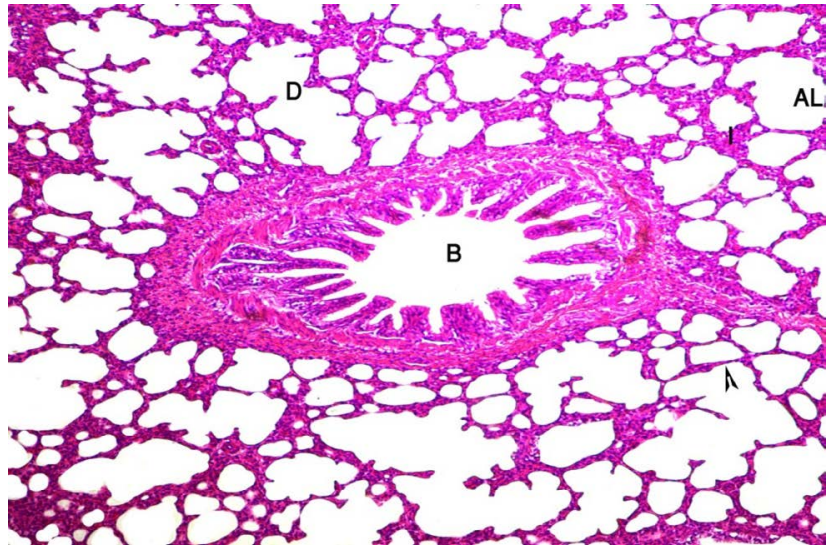

Figure 10: A photomicrograph of a section in rat lung of Group $V$ showing many alveoli (AV) of variable size,alveolar ducts (D). Some thickened interalveolar septa are seen studded with mononuclear cellular infiltration (I), whereas others are apparently thin (arrowhead $\boldsymbol{\Delta})(\mathrm{H}$ and E, X200).

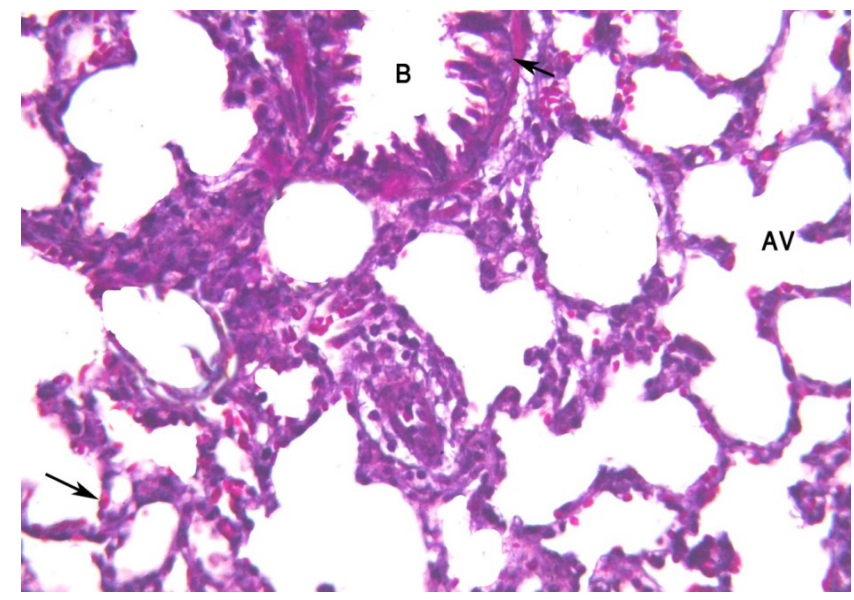

Figure 11: A photomicrograph of a section in rat lung of Group I showing the alveoli (AV) with the presence of minimal amount of collagen fibers in the interalveolar septa (arrow $\uparrow$ ) and around bronchiole (B) (Masson's trichrome, X400).

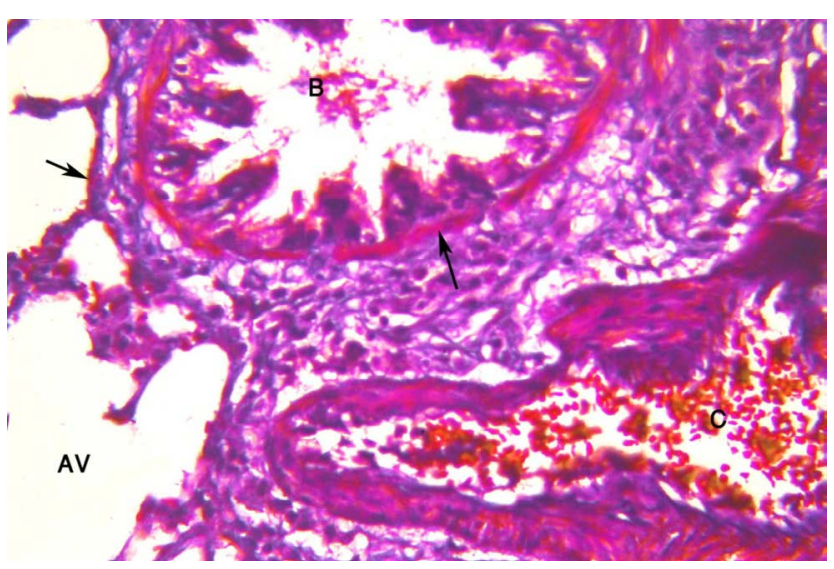

Figure 12: A photomicrograph of a section in rat lung of Group II showing extensive accumulation of collagen fibers around alveoli (AV), within the interalveolar septa (arrow $\uparrow$ ) around bronchiole (B). Notice congested blood vessels ( C) (Masson's trichrome, X400). 
Citation: MAltaib Z, EMansy A, EIMahlawy AM, Sabry D (2017) The Possible Ameliorative Effect of Mesenchymal Stem Cells and Curcumin Onbleomycin Induced Lung Injuries in the Adult Male Rats: Histological and Immunohistochemical Study. J Stem Cell Res Ther 7: 389. doi: 10.4172/2157-7633.1000389

presence of minimal amount of collagen fibers in the interalveolar septa around bronchiole (Figure 11).

Group II (bleomycin group): This group showed extensive accumulation of collagen fibers around alveoli, within the interalveolar septa and around bronchiole. The congested blood vessel was seen (Figure 12).

Group III (curcumin and bleomycin group): This group showed moderate accumulation of collagen fibers around alveoli, within the interalveolar septa and around bronchioles (Figure 13).

Group IV (stem cell and bleomycin group): This group showed mild accumulation of collagen fibers around alveoli, within the interalveolar septa and around bronchioles (Figure 14).

Group V (curcumin, stem cell and bleomycin group): This group showed minimal accumulation of collagen fibers around alveoli, within the interalveolar septa and around bronchioles (Figure 15).

\section{Orceinstain}

Group I (control group): Sections of control rat revealed continuous reddish brown elastic fibers around the bronchiole, and walls of the alveoli (Figure 16).

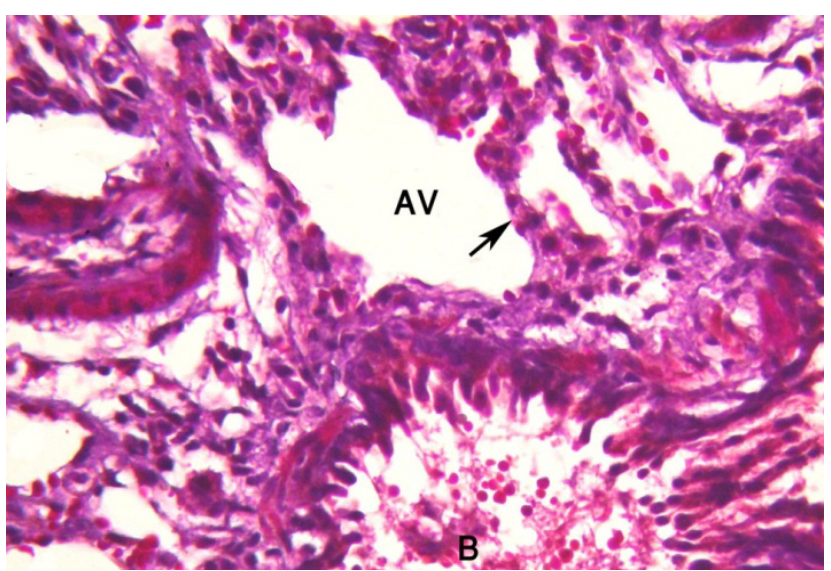

Figure 13: A photomicrograph of a section in rat lung of Group III showing moderate accumulation of collagen fibers around alveoli (AV), within the interalveolar septa (arrow $\uparrow$ ) and around bronchioles (B) (Masson's trichrome, X400).

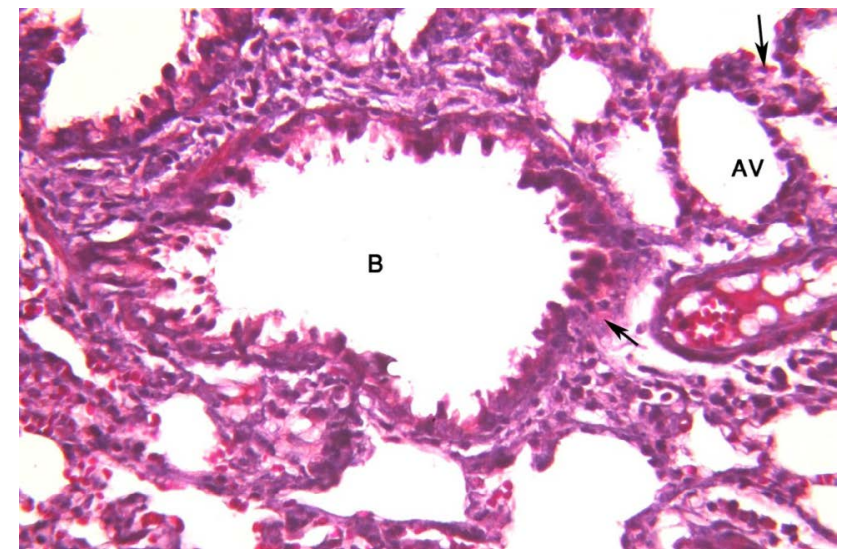

Figure 14: A photomicrograph of a section in rat lung of Group IV showing mild accumulation of collagen fibers around alveoli (AV), within the interalveolar septa (arrow $\uparrow$ ) and around bronchioles (B) (Masson's trichrome, X400).

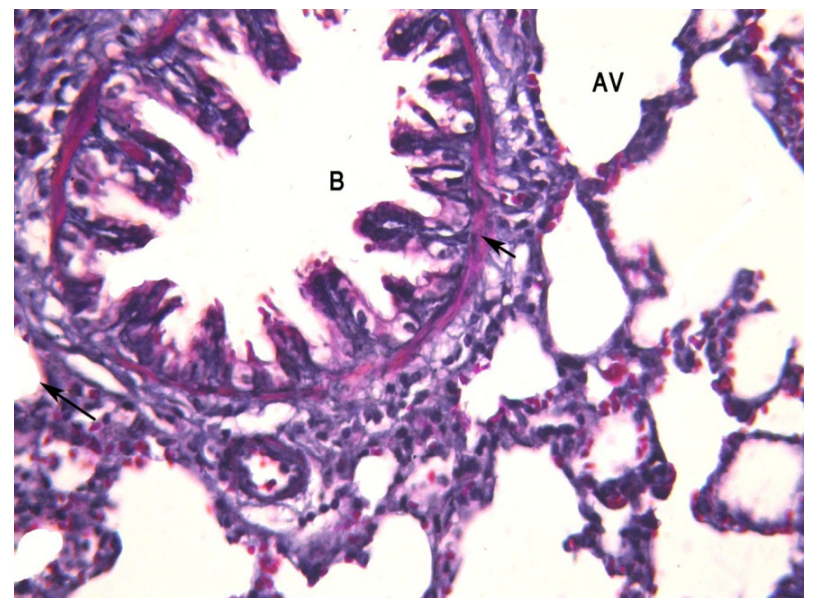

Figure 15: A photomicrograph of a section in rat lung of Group V showing minimal accumulation of collagen fibers around alveoli (AV), within the interalveolar septa (arrow $\uparrow$ ) and around bronchioles (B) (Masson's trichrome, $\mathrm{X} 400)$.

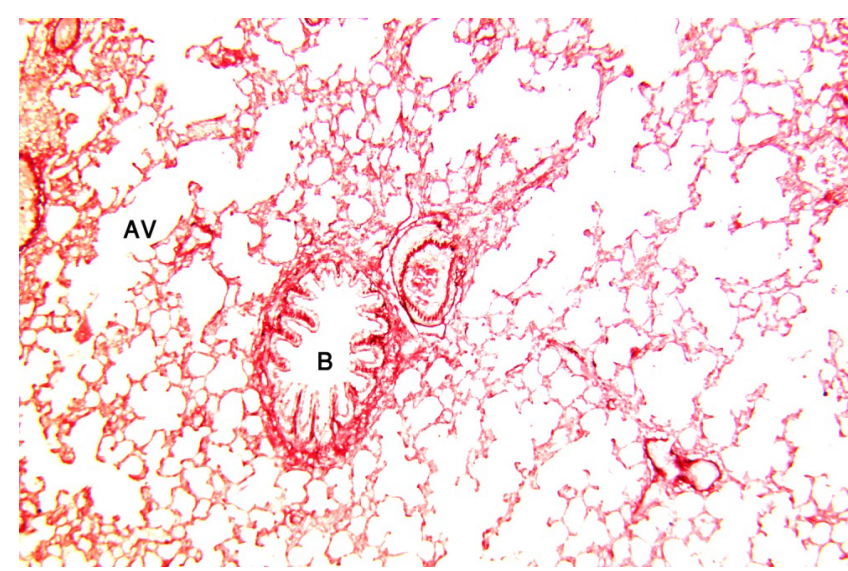

Figure 16: A photomicrograph of a section in rat lung of Group I showing continuous reddish brown elastic fibers around the bronchiole $(B)$, and walls of the alveoli (AV) (Orcein stain, X100).

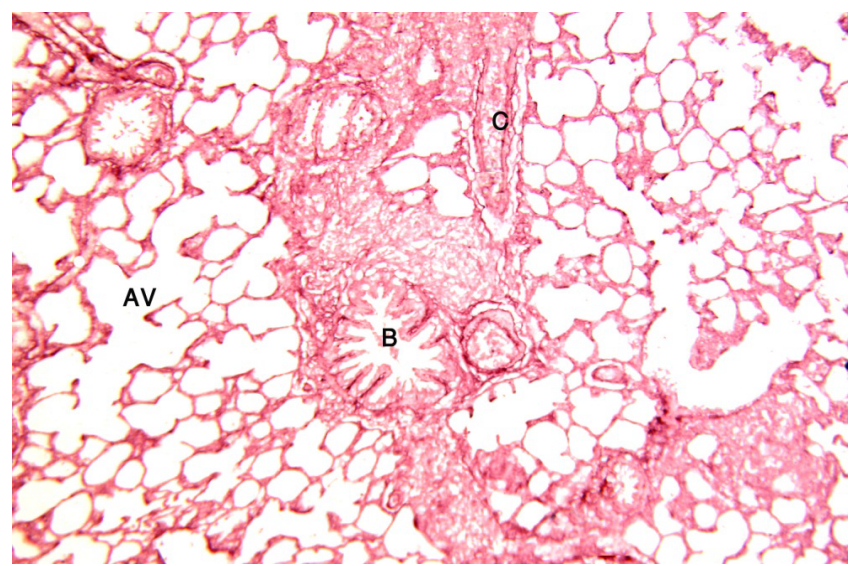

Figure 17: A photomicrograph of a section in rat lung of Group II showing extensive accumulation of reddish brown elastic fibers around the bronchiole (B), wall of dilated congested blood vessel (C), and walls of the alveoli (AV) (Orcein stain, X100). 
Citation: MAltaib Z, EMansy A, EIMahlawy AM, Sabry D (2017) The Possible Ameliorative Effect of Mesenchymal Stem Cells and Curcumin Onbleomycin Induced Lung Injuries in the Adult Male Rats: Histological and Immunohistochemical Study. J Stem Cell Res Ther 7: 389 . doi: $10.4172 / 2157-7633.1000389$

Group II (bleomycin group): This group showed extensive accumulation of reddish brown elastic fibers around the bronchiole, wall of dilated congested blood vessel, and walls of the alveoli (Figure 17).

Group III (curcumin and bleomycin group): This group showed moderate accumulation of reddish brown elastic fibers in the bronchiole, wall of dilated congested blood vessel, and walls of the alveoli (Figure 18).

Group IV (stem cell and bleomycin group): This group showed mild accumulation of reddish brown elastic fibers around the bronchiole, wall of congested blood vessel, and walls of the alveoli (Figure 19).

Group V (curcumin, stem cell and bleomycing group): This group showed minimal accumulation of reddish brown elastic fibers in the bronchiole, wall of congested blood vessel, and walls of the alveoli (Figure 20).

\section{Immunohistochemical result}

\section{PCNA immunohistochemical stain}

Group I (control group): Sections of control ratrevealed few positive PCNA immunoreactivity within the nuclei of cells lining alveoli and nuclei of bronchiolar epithelium (Figure 21).

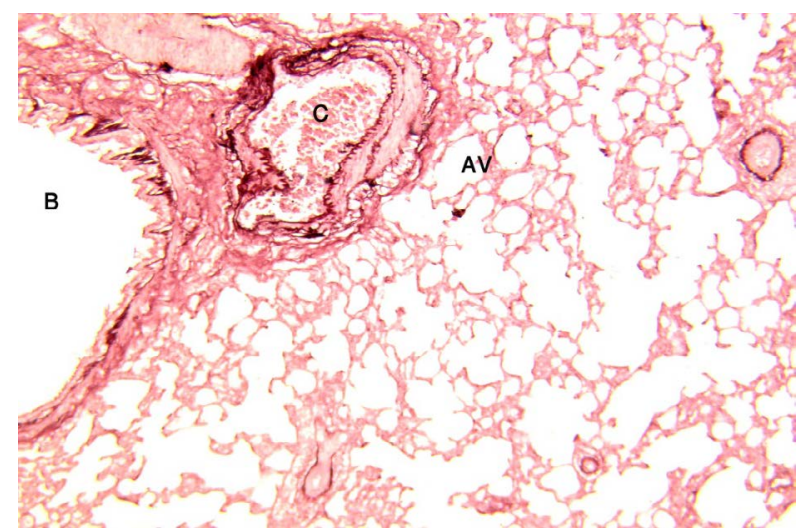

Figure 18: A photomicrograph of a section in rat lung of Group III showing moderate accumulation of reddish brown elastic fibers around the bronchiole (B), wall of dilated congested blood vessel (C), and walls of the alveoli (AV) (Orcein stain, X100).

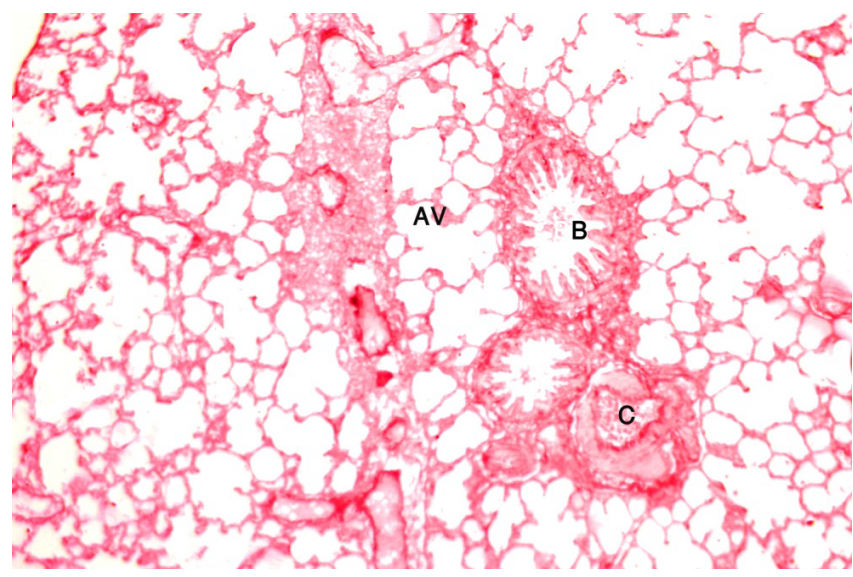

Figure 19: A photomicrograph of a section in rat lung of Group IV mild accumulation of reddish brown elastic fibers around the bronchiole (B), wall of congested blood vessel (C), and walls of the alveoli (AV) (Orcein stain, X100).

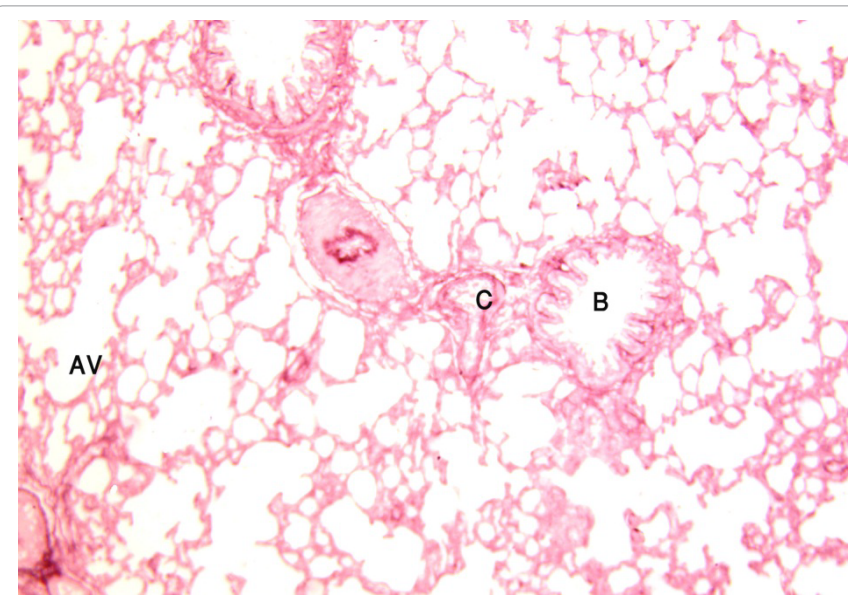

Figure 20: A photomicrograph of a section in rat lung of Group $V$ showing minimal amount of reddish brown elastic fibers around the bronchiole passages (B), wall of congested blood vessel (C), and walls of the alveoli (AV) (Orcein stain, $\mathrm{X} 100$ ).

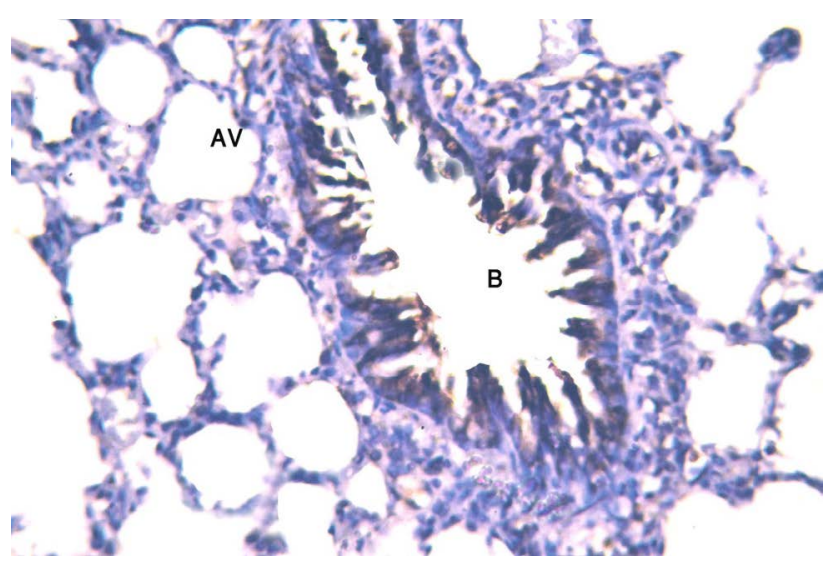

Figure 21: A photomicrograph of a section in rat lung of Group I showing few positive PCNA immunoreactivity within the nuclei of cells lining alveoli (AV) and nuclei of bronchiolar epithelium (B) (Immunostaining for PCNA X400).

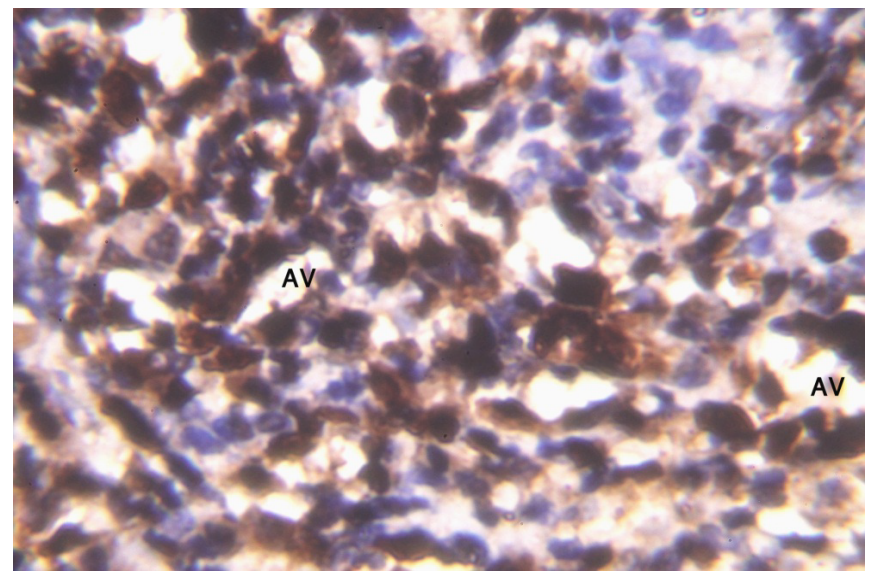

Figure 22: A photomicrograph of a section in rat lung of Group II showing positive PCNA immune reactivity within the nuclei of cells lining alveoli (AV) (Immunostaining for PCNA X400). 
Citation: MAltaib Z, EMansy A, EIMahlawy AM, Sabry D (2017) The Possible Ameliorative Effect of Mesenchymal Stem Cells and Curcumin Onbleomycin Induced Lung Injuries in the Adult Male Rats: Histological and Immunohistochemical Study. J Stem Cell Res Ther 7: 389 . doi: 10.4172/2157-7633.1000389

Group II (bleomycin group): This group showed positive PCNA immunoreactivity within the nuclei of cells lining alveoli (Figure 22).

Group III (curcumin and bleomycin group): This group showed moderate positive PCNA immunoreactivity within the nuclei of cells lining alveoli (Figure 23).

Group IV (stem cell and bleomycingroup): This group showed mild positive PCNA immunoreactivity within the nuclei of cells lining alveoli (Figure 24).

Group V (curcumin, stem celland bleomycin group): This group showed weak positive PCNA immunoreactivity within the nuclei of cells lining alveoli and nuclei of bronchiolar epithelium (Figure 25).

\section{COX2 immunohistochemical stain}

Group I (control group): Sections of control ratrevealed positive COX2 immunoreactivity within cytoplasmic of alveolar epithelial cells and in the bronchiolar epithelium (Figure 26).

Group II (bleomycin group): This group showed marked positive COX2 immunoreactivity within cytoplasmic of alveolar epithelial cells

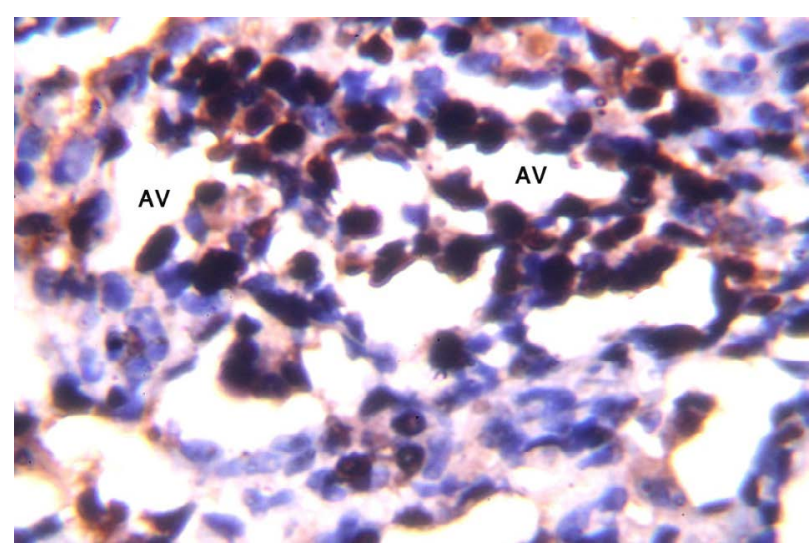

Figure 23: A photomicrograph of a section in rat lung of Group III moderate positive PCNA immunoreactivity within the nuclei of cells lining alveoli (AV) (Immunostaining for PCNA X400).

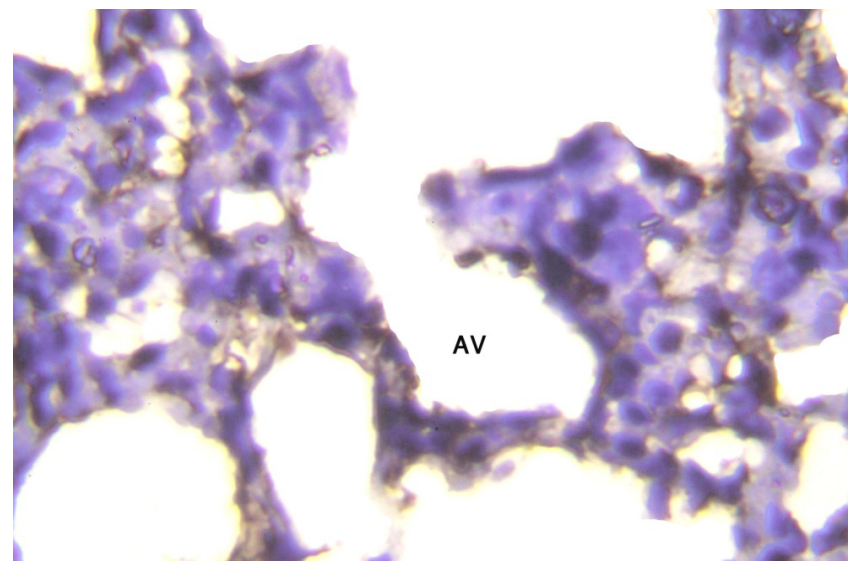

Figure 24: A photomicrograph of a section in rat lung of Group IV showing mild positive PCNA immunoreactivity within the nuclei of cells lining alveoli (AV) (Immunostaining for PCNA X400).

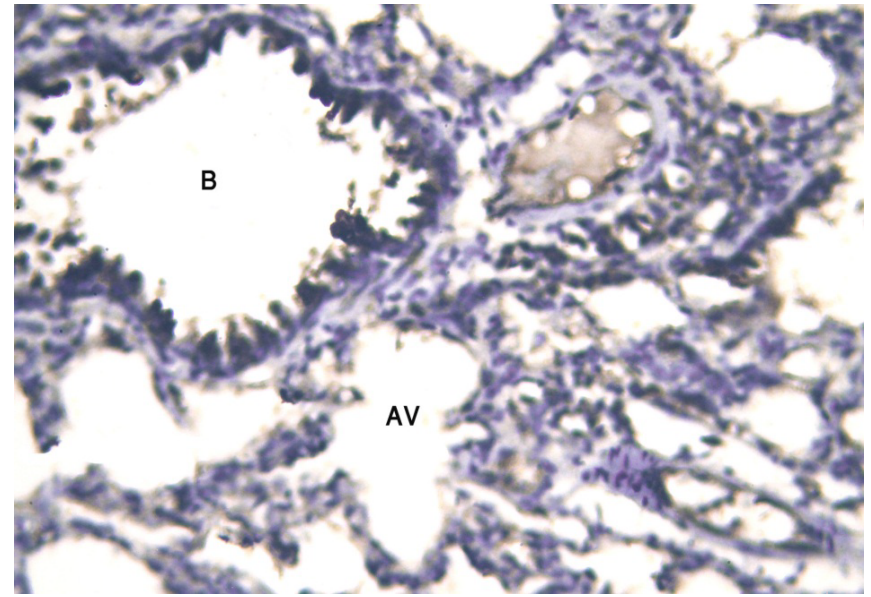

Figure 25: A photomicrograph of a section in rat lung of Group $V$ showing weak positive PCNA immunoreactivity within the nuclei of cells lining alveoli (AV) and nuclei of bronchiolar epithelium (B) (Immunostaining for PCNA X400).

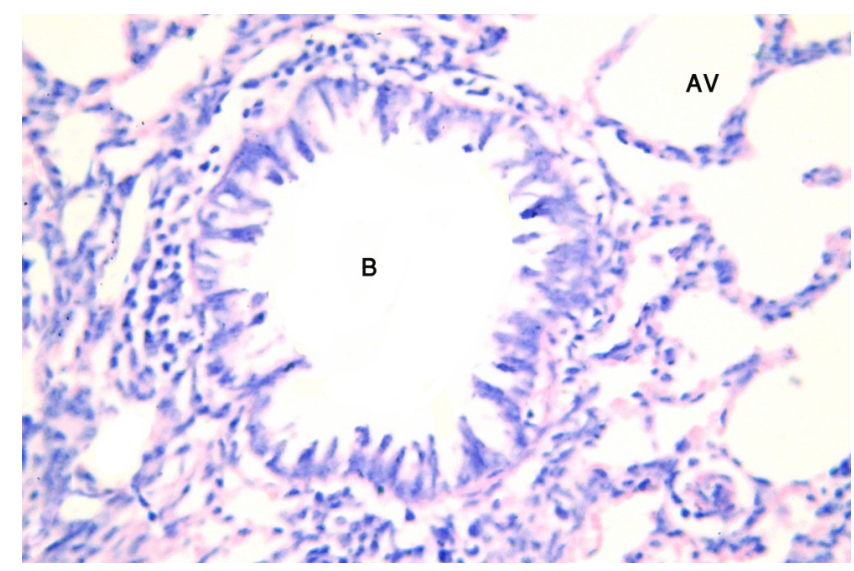

Figure 26: A photomicrograph of a section in rat lung of Group I showing positive COX2 immunoreactivity within cytoplasmic of alveolar epithelial cells (AV) and in the bronchiolar epithelium (B) (Immunostaining for COX2 X400).

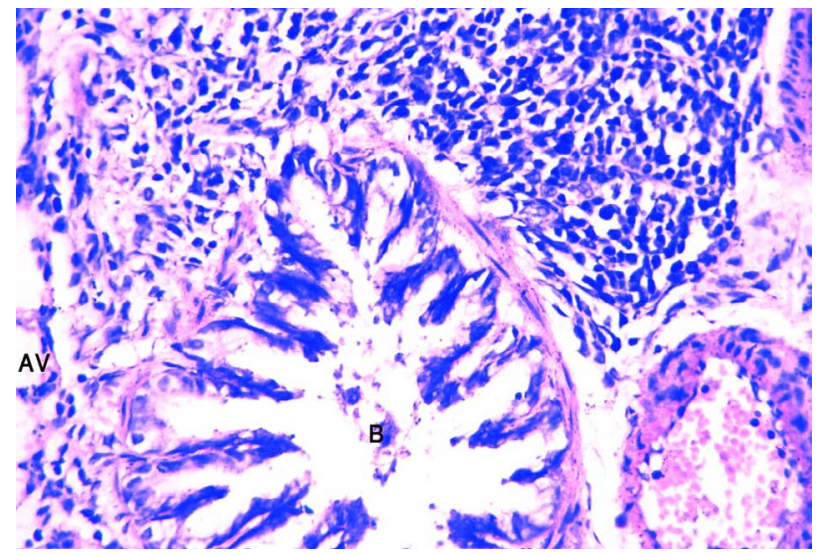

Figure 27: A photomicrograph of a section in rat lung of Group II showing marked positive COX2 immunoreactivity within cytoplasmic of alveolar epithelial cells (AV) and in the bronchiolar epithelium (B) (Immunostaining for COX2 X400). 
Citation: MAltaib Z, EMansy A, EIMahlawy AM, Sabry D (2017) The Possible Ameliorative Effect of Mesenchymal Stem Cells and Curcumin Onbleomycin Induced Lung Injuries in the Adult Male Rats: Histological and Immunohistochemical Study. J Stem Cell Res Ther 7: 389 . doi: $10.4172 / 2157-7633.1000389$

and in the bronchiolar epithelium (Figure 27).

Group III (curcumin and bleomycin group): This group showed moderate positive COX2 immunoreactivity within cytoplasmic of alveolar epithelial cells and in the bronchiolar epithelium (Figure 28).

Group IV (stem cell and bleomycingroup): This group showed mild positive COX2 immunoreactivity within cytoplasmic of alveolar epithelial cells and in the bronchiolar epithelium (Figure 29).

Group V (curcumin, stem cell and bleomycin group): This group showed weak positive COX2 immunoreactivity within cytoplasmic of alveolar epithelial cells and in the bronchiolar epithelium (Figure 30).

\section{Morphometric results}

The mean area\% of collagen fibers stained with massontrichrome and elastic fibers stained with orcein for all groups are presented in Tables 1 and 2 and Figures 31 and 32. The area\% of collagen fibers and elastic fibers accumulation in the inter alveolar septa and around the bronchiole showed a significant increase in group II, III when compared to control group $(\mathrm{P}<0.05)$, but no statistically significant difference were recorded between groups II and III. The area\% of collagen fibers and elastic fibers accumulation in the inter alveolar septa and around the

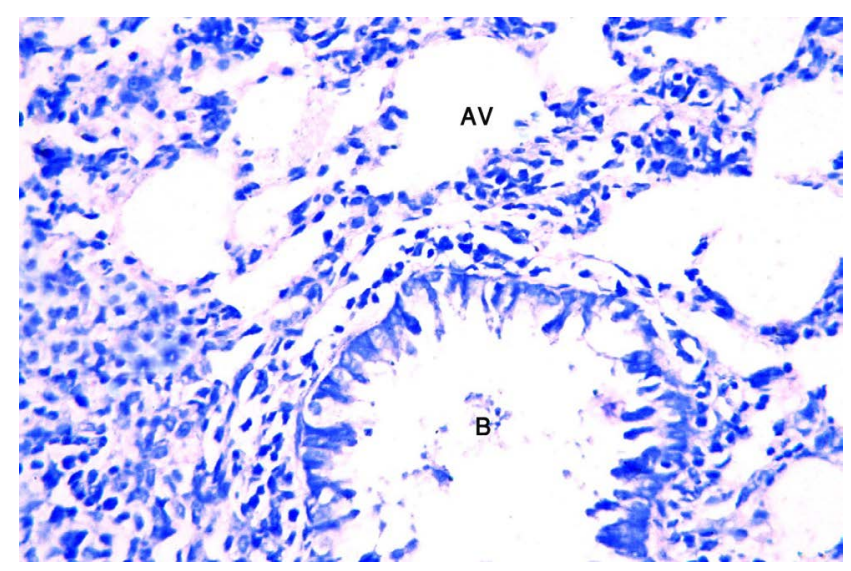

Figure 28: A photomicrograph of a section in rat lung of Group III showing moderate positive COX2 immunoreactivity within cytoplasmic of alveolar epithelial cells (AV) and in the bronchiolar epithelium (B) (Immunostaining for COX2 X400).

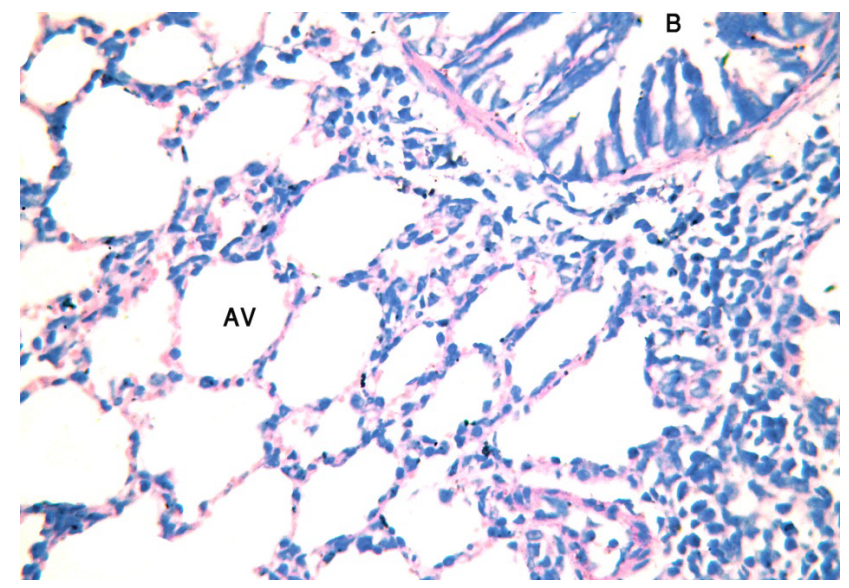

Figure 29: A photomicrograph of a section in rat lung of Group IV showing mild positive COX2 immunoreactivity within cytoplasmic of alveolar epithelial cells (AV) and in the bronchiolar epithelium (B) (Immunostaining for COX2 X400).

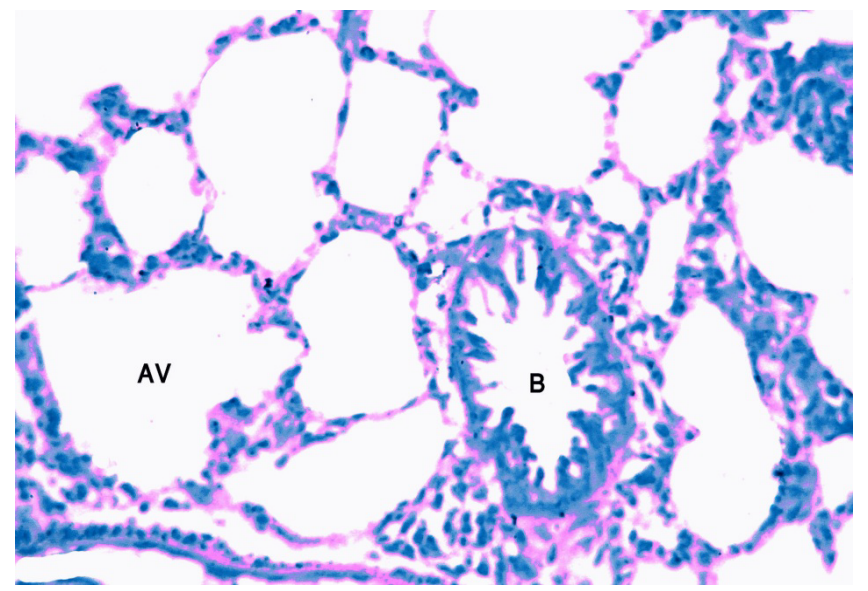

Figure 30: A photomicrograph of a section in rat lung of Group V showing weak positive COX2 immunoreactivity within cytoplasmic of Alveolar Epithelial Cells (AV) and in the bronchiolar epithelium (B). (Immunostaining for COX2 X400).

\begin{tabular}{|c|c|}
\hline Groups & Mean $\% \pm$ SD of affected inter alveolarsepta around bronchiole \\
\hline Group I & $4.65 \pm 3.77$ \\
\hline Group II & $14.22 \pm 2.25^{\mathrm{a}}$ \\
\hline Group III & $11.19 \pm 2.26^{\mathrm{a}}$ \\
\hline Group IV & $7.06 \pm 2.76^{\mathrm{a}}$ \\
\hline Group V & $5.07 \pm 2.98^{\mathrm{a}}$ \\
\hline
\end{tabular}

Table 1: Showing the mean area $\% \pm S D$ of collagen fibers in all experimental groups. Group II compared with Group I. Group IV and V compared with Group II. a: Significantly different from the value from the control group at $p<0.05$.

\begin{tabular}{|c|c|}
\hline Groups & Mean $\% \pm$ SD of affected elastic fibers around the bronchiole \\
\hline Group I & $5.22 \pm 4.89$ \\
\hline Group II & $13.8 .22 \pm 3.23^{\mathrm{a}}$ \\
\hline Group III & $10.08 \pm 4.33^{\mathrm{a}}$ \\
\hline Group IV & $7.86 \pm 1.92^{\mathrm{a}}$ \\
\hline Group V & $6.07 \pm 2.72^{\mathrm{a}}$ \\
\hline
\end{tabular}

Table 2: Mean area percentage of $\% \pm S D$ of elastic fibers in all experimental groups. Group II compared with Group I. Group IV and V compared with Group II. a: Significantly different from the value from the control group at $p<0.05$.

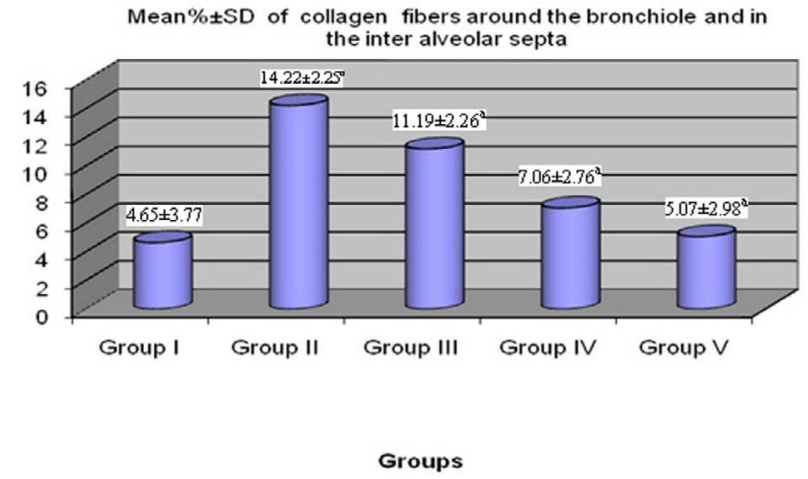

Figure 31: Showing the mean area\% of collagen fibers in all experimental groups.

bronchiole showed a significant decrease in groups IV and $\mathrm{V}$ when compared to control group $(\mathrm{P}<0.05)$. 
Citation: MAltaib Z, EMansy A, EIMahlawy AM, Sabry D (2017) The Possible Ameliorative Effect of Mesenchymal Stem Cells and Curcumin Onbleomycin Induced Lung Injuries in the Adult Male Rats: Histological and Immunohistochemical Study. J Stem Cell Res Ther 7: 389 . doi: 10.4172/2157-7633.1000389

Page 10 of 13

\begin{tabular}{|c|c|}
\hline Groups & $\begin{array}{c}\text { Mean } \% \pm \text { SD of PCNA within the nuclei of cells lining } \\
\text { affected alveoli }\end{array}$ \\
\hline Group I & $2.17 \pm 0.52$ \\
\hline Group II & $12.01 \pm 1.2^{\mathrm{a}}$ \\
\hline Group III & $10.56 \pm 1.09^{\mathrm{a}}$ \\
\hline Group IV & $4.1 \pm 2.52^{\mathrm{a}}$ \\
\hline Group V & $3.09 \pm 0.13^{\mathrm{a}}$ \\
\hline
\end{tabular}

Table 3: Showing the mean area $\% \pm$ SD of PCNA positive nuclei of cells lining alveoliin all experimental groups. Group II compared with Group I. Group IV and $\checkmark$ compared with Group II. a: Significantly different from the value from the control group at $p<0.05$

\begin{tabular}{|c|c|}
\hline Groups & $\begin{array}{c}\text { Mean\% } \pm \text { SD of COX2 immunoreactivity within cytoplasmic of } \\
\text { alveolar epithelial cells and in the bronchiolar epithelium }\end{array}$ \\
\hline Group I & $3.09 \pm 0.42$ \\
\hline Group II & $13.12 \pm 1.6^{\mathrm{a}}$ \\
\hline Group III & $11.45 \pm 1.12^{\mathrm{a}}$ \\
\hline Group IV & $5.0 \pm 2.83^{\mathrm{a}}$ \\
\hline Group V & $3.99 \pm 0.21^{\mathrm{a}}$ \\
\hline
\end{tabular}

Table 4: Showing the mean area $\% \pm$ SD of COX2 immunoreactivity within cytoplasmic of alveolar epithelial cells and in the bronchiolar epithelium in all experimental groups. Group II compared with group I. Group IV and V compared with Group II. a: Significantly different from the value from the control group at $p<0.05$.

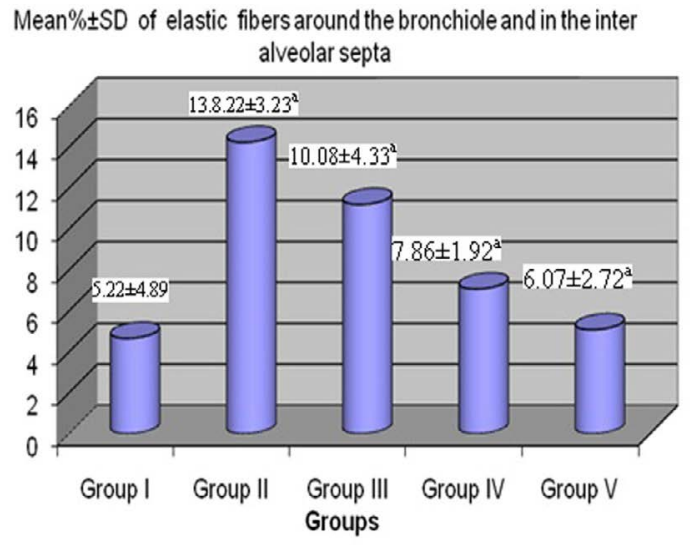

Figure 32: Showing the mean area\% of elastic fibers in all experimental groups.

Mean $\% \pm S D$ of PCNA within the nuclei of cells lining affected alveoli

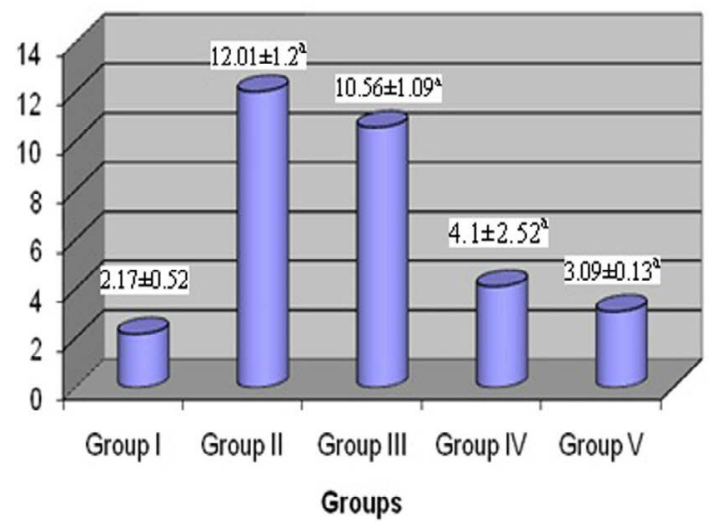

Figure 33: Showing the mean area\% of PCNA positive immunoreactivity within the nuclei of cells lining alveoli in all experimental groups.
Mean $\% \pm S D$ of COX2 immunoreactivity within cytoplasmic of alveolar epithelial cells and in the bronchiolar epithelium

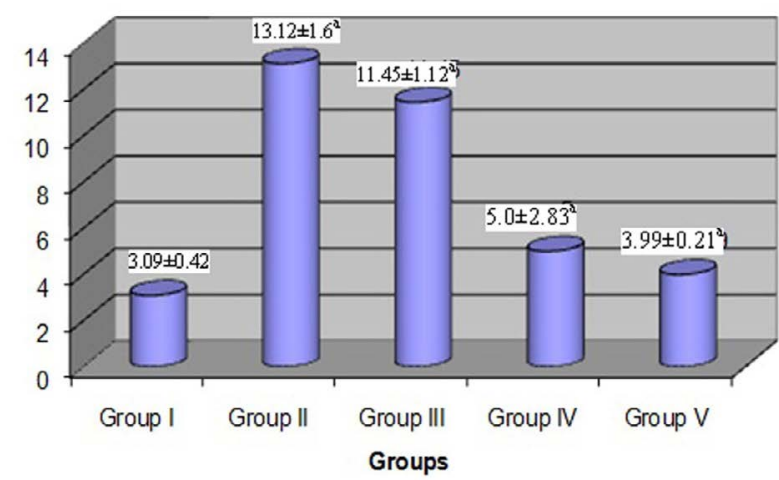

Figure 34: Showing the mean area\% of COX2 immunoreactivity within cytoplasmic of alveolar epithelial cells and in the bronchiolar epithelium in all experimental groups.

The mean area\% of PCNA and COX 2 for all groups are presented in Tables 3 and 4 and Figures 33 and 34. The area\% of PCNA positive immunoreactivity within the nuclei of cells lining alveoli and COX2 immunoreactivity within cytoplasmic of alveolar epithelial cells and in the bronchiolar epithelium showed a significant increase in group II,III when compared to control group $(\mathrm{P}<0.05)$, but no statistically significant difference were recorded between groups II and III. The area\% of PCNA positive immunoreactivity within the nuclei of cells lining alveoli and COX2 immunoreactivity within cytoplasmic of alveolar epithelial cells and in the bronchiolar epithelium showed a significant decrease in groups IV and V when compared to control group $(\mathrm{P}<0.05)$.

\section{Biochemical results}

As shown in Table 5, in group II compared to control group, The MDA and TNF- $\alpha$ were highly significantly increased $(\mathrm{P}<0.01)$ but were significantly decreased in group $\mathrm{V}$ compared to group II $(\mathrm{P}<0.05)$. Reduced GSH was highly significantly decreased in group II compared to control group I $(\mathrm{P}<0.01)$, but was significantly increased in group $\mathrm{V}$ compared to group II $(\mathrm{P}<0.05)$.

\section{Discussion}

Pulmonary fibrosis is a specific form of chronic interstitial lung disease which is associated with the histological appearance of usual interstitial pneumonia and having a poor prognosis [3].

The histological examination of lung sections of group II of the present study revealed various changes such as many collapsed alveoli, while other alveoli were dilated and ruptured. The bronchiole lined by epithelial cells with deeply stained nuclei and its lumen was full of exfoliated epithelial cells. Heavy mononuclear cellular infiltration surrounding the bronchioles and in the interalveolar septa. The dilated and congested blood vessels and interstitial hemorrhage in the alveolar spaces were seen. Moreover, a significant increase in the amount of collagen and elastic fibers around bronchiole and the walls of the alveoli.

Our results are in agreement with previous researchers [7,25-27], who mentioned that BLM was associated with diffuse mononuclear cellular infiltration surrounding the bronchioles and the interalveolar septa with diffuse thickening of the interalveolar septa.

Some authors $[2,26]$ clarified that intratracheal BLM can stimulate endothelia cell, macrophage and fibroblast to induce inflammatory 
Citation: MAltaib Z, EMansy A, EIMahlawy AM, Sabry D (2017) The Possible Ameliorative Effect of Mesenchymal Stem Cells and Curcumin Onbleomycin Induced Lung Injuries in the Adult Male Rats: Histological and Immunohistochemical Study. J Stem Cell Res Ther 7: 389. doi: 10.4172/2157-7633.1000389

Page 11 of 13

\begin{tabular}{|c|c|c|c|c|}
\hline & Group I & Group II & Group III & Group IV \\
\hline MDA nmol/g tissue & $34.6 \pm 1.82$ & $75.76 \pm 5.7^{* *}$ & $37.24 \pm 1.06$ & $38.25 \pm 2.41^{*}$ \\
\hline GSH $\mathbf{\mu g} / \mathbf{m g}$ tissue & $1.50 \pm 0.16$ & $0.77 \pm 0.22^{* *}$ & $1.48 \pm 0.20$ & $35.26 \pm 2.30^{\star}$ \\
\hline TNF-a (Pg/mI) & $16.36 \pm 7.7$ & $30.1 \pm 15.6^{* *}$ & $15.4 \pm 8.1$ & $1.60 \pm 0.51^{*}$ \\
\hline
\end{tabular}

Table 5: Showing changes in the malondialdehyde (MDA), reduced glutathione (GSH) and TNF- $\alpha$ in all experimental groups. SD=standard deviation, highly significant ${ }^{\star *}$ for Group II compared with Group I and significant* for Group III. Group IV and Group V compared with Group II.

mediator. The inflammatory mediator will induce proinflammatory cytokines, cytokine fibrogenic, transforming growth factor- $\beta$ (TGF- $\beta$ ), apoptosis and the release of free radicals, finally resulting in fibrosis. Also damage and activation of alveolar epithelial cells may result in the release of cytokines and growth factors that can simulate the proliferation of myofibroblast and secretion of pathologic extracellular matrix, leading to fibrosis that interfere with the normal lung architecture and disable gas exchange in the lungs.

In our results the diffuse mononuclear cellular infiltration surrounding the bronchioles and the interalveolar septa was supported with a significant increase COX2 within cytoplasmic of alveolar epithelial cells and in the bronchiolar epithelium.

Other previous studies $[8,28]$ showed that Cox-2 and Cox metabolites were involved in the development and progression of Acute Lung Injury (ALI) in animal models. ALI was associated with increased Cox-2 gene expression in murine lungs. Cox-2 was known to be upregulated in inflammatory diseases and in the generation of pro inflammatory signals and cytokines.

A significant increase in the number of brown PCNA positive nuclei among cells lining alveoli and nuclei of bronchiolar epithelium were seen in group II of the present study. Our result in accordance with some researchers [29].

Some investigators [30] reported that PCNA had been also found to induce apoptosis in cells subjected to oxidative stress.

Our studied group II revealed highly significant increase of MDA and TNF- $\alpha$ with a significant decrease of GSH as compared to control group. These results were in agreement with the previous studies [7]. In our study we used the presence of TNF- $\alpha$ in lungs as an indicator of pulmonary inflammation and fibrosis.

Some researchers $[7,26]$ demonstrated that the mechanism of action of BLM was mediated through the production of free radicals and reactive oxygen species (ROS). ROS generated from BLM forming complexes with iron and damages important macromolecules like proteins, lipids and DNA and also could cause damage to epithelial and endothelial cells in lung tissue, eventually leading to the impairment of cell functioning, cytolysis and interstitial fibrosis.

Such histological alterations and immunohistochemical changes of the lung tissue in group II of the present study were supported, biochemically.

The histological examination of lung sections of group III of the present study revealed showed little improvement on BLM induced lung injuries such as many collapsed alveoli, while other alveoli were dilated and ruptured. Few mononuclear cellular infiltration surrounding the bronchioles and in the interalveolar septa, as well as the extravasated red blood cells and congested blood vessels were seen. Moreover a significant increase of collagen and elastic fibers around alveoli, within the interalveolar septa and around bronchioles as compared to control group but were fewer than in group II.

Our results are in agreement with previous researchers $[2,31,32]$,who stated that there was inhibiting neutrophil infiltration, suppression of proinflammatory cytokines in alveolar macrophages, prevents the formation of ROS and scavenges free radicals andenhances the activities of antioxidantsuch as superoxide dismutasein rats given oral curcumin treatment after single dose bleomycin induction by intratracheal, as well as other acute lung injury in animal models.

A significant increase in the number of brown PCNA positive nuclei and COX2 within cytoplasmic of alveolar epithelial cells and in the bronchiolar epithelium in group III as compared to control group, but were fewer than in group II of the present study.

In agreement with our results, several researches $[8,16]$ have proven that curcumin mediates its anti-inflammatory effect through the downregulation of enzymes (such as Cox-2 and 5-lipoxygenase) and cytokines such as TNF, IL-1, and IL-6.

Our studied group III revealed significant decrease of MDA and TNF- $\alpha$ with a significant increase of GSH as compared to control group. These results were in agreement with the previous studies $[8,16,31]$.

The histological examination of lung sections of group IV of the present study revealed some collapsed alveoli, while other alveoli are dilated and ruptured. Few mononuclear cellular infiltration surrounding the bronchioles and in the interalveolar septa were seen. Moreover a significant decrease of collagen and elastic fibers around alveoli, within the interalveolar septa and around bronchioles as compared to control group.

Our results are in agreement with other investigators [15,33], who proved that MSCs can attenuate bleomycin-induced lung injury by down modulating the inflammatory responses, secretion of proinflammatory cytokines and ameliorating fibrosis.

A significant decrease in the number of brown PCNA positive nuclei and COX2 within cytoplasmic of alveolar epithelial cells and in the bronchiolar epithelium in group IV as compared to control group.

Further studies [29] proved that early treatment with MSCs may produce antagonists to tumor necrosis factor or other cytokines that disrupt signal pathways reducing the extent of inflammation within the lung as well as acceleration of resolution of fibrosis is by epithelial restitution, also stated that MSCs restore cytoskeletal reorganization in alveolar epithelial cells.

Our studied group IV revealed significant decrease of MDA and TNF- $\alpha$ with a significant increase of GSH as compared to control group. These results were in agreement with the previous studies [34], who reported that MSCs decreased anti-inflammatory effect, oxidative stress in the lung tissue and increased antioxidant activity as (GSH) by the secretion of soluble growth factors, or the interaction of MSCs with host cells, or both.

MSCs has possible multifactorial mechanisms to limit experimentally-induced lung injury and protect the lung tissues such as modulating the oxidative stress reaction, inflammatory response, 
Citation: MAltaib Z, EMansy A, EIMahlawy AM, Sabry D (2017) The Possible Ameliorative Effect of Mesenchymal Stem Cells and Curcumin Onbleomycin Induced Lung Injuries in the Adult Male Rats: Histological and Immunohistochemical Study. J Stem Cell Res Ther 7: 389 . doi: 10.4172/2157-7633.1000389

Page 12 of 13

tissue damage and repair and protection of the alveolar epithelial and pulmonary capillary endothelium barrier function [34].

Epigenetic regulation of gene expression has an important role in normal, malignant tissue development and regeneration. The differentiation of MSC is under epigenetic control, such as DNA methylation, histone modification, chromatin remodeling, microRNAs and post-translational modifications [35]. Some previous studies [36] proved that both the proper DNA methylation and histone modifications play a critical role during the cell fate determination of mesenchymal stem cells. Yang and his colleagues (2015) [37] revealed that inhibition the catalytic activity of H3K9 histone modifiers, G9a, also known as Ehmt2, is able to convert bone marrow derived mesenchymal stem cells to cardiac competent progenitors. Moreover, the differentiation of MSCs into osteoblast requires an active DNA demethylation, depositing and removal of DNA methylation are also essential for the lineage commitment of mesenchymal stem cells [38]. Interestingly, as histone methyl transferases G9a and GLP physically interact with DNA methyltransferase and maintain DNA methylation in Embryonic Stem (ES) cells investigation the chromatin loading and catalytic activity of these histone modifiers before and after the MSCs undergo differentiation might direct on identifying the genes that involved in the maintenance and differentiation of MSCs [39].

The efficacy of cell therapies mainly depends on appropriate control of the fate and function of the engrafted cells. Therefore, strategies for enhancing stem cell survival, proliferation, and differentiation have become one of the best goal and the most interest for the researchers. The application of an adjuvant drug is a promising method to support stem cell therapy [11].

In the present study group $\mathrm{V}$ revealed a marked improvement of biochemical parameter, histological changes of lung. Moreover, a significant decrease in the number of brown PCNA positive nuclei and COX2 within cytoplasmic of alveolar epithelial cells and in the bronchiolar epithelium in group $\mathrm{V}$ as compared to control group.

These results are in agreement and confirming the findings of some researchers who proved that the combining of the natural antioxidant products treatment with MSCs potentiated the therapeutic effect of MSCs injection and had a significant beneficial effect over the MSCs therapy alone [34].

Some studies explained that antioxidant levels are regulated within the cell and a small change in the redox state can significantly affect cell behavior, stem cell characteristics and survival. Cells at the site of tissue injury can detect the oxidative and inflammatory stresses, which can lead to cellular aging and/or apoptosis. Thus, the increasing the cellular antioxidant levels before MSCs transplantation could further increase stem cell survival and thereby improve functional repair and organ injuries $[11,40,41]$.

\section{Conclusion}

Bone marrow derived mesenchymal stem cells (BMSCs) can attenuate bleomycin induced lung injuries in rats but curcumin can yield better beneficial effect over the BMSCs therapy alone.

\section{Conflict of Interest}

There are no conflicts of interest.

\section{References}

1. Zhu B, Ma AQ, Yang L, Dang XM (2013) Atorvastatin attenuates bleomycininduced pulmonary fibrosis via suppressing iNOS expression and the CTGF

\section{(CCN2)/ERK signaling pathway. Int J Mol Sci 14: 24476-24491.}

2. Rahmi A, Setiyono A, Juniantito V (2015) Curcumin effect on Bleomycininduced pulmonary fibrosis in Mus musculus. IJAVS 20: 148-157.

3. Görmeli CA, Saraç K, Çiftçi O, Timurkaan N, Malkoç S (2016) The effects of hesperidin on idiopathic pulmonary fibrosis evaluated by histopathologialbiochemical and micro-computed tomography examinations in a bleomycin-rat model. Biomed Res 27: 737-742.

4. El-Gamal MA, Zaitone SA, Moustafa YM (2013) Role of irbesartan in protection against pulmonary toxicity induced by bleomycin in rats. IOSRPHR 3: 38-47.

5. Abd El Salam NF, Hafez MS, Omar SM, El Sayed HF (2015) The role of bone marrow-derived mesenchymal stem cells in a rat model of paraquat-induced lung fibrosis: a histological and immunohistochemical study. Egyptian $\mathrm{J}$ Histol 38: $389-401$.

6. Aytemur ZA, Hacievliyagil SS, Iraz M, Samdanci E, Ozerol E, et al. (2012) Effects of iloprost on bleomycin-induced pulmonary fibrosis in rats compared with methyl prednisolone. Rev Port Pneumol 18: 272-277. [PubMed]

7. Mousa AM (2016) Effect of pirfenidone on bleomycin induced pulmonary alveolar fibrosis in adult male rats. histological, immunohistochemical, morphometrical and biochemical study. IJCDA 2: 17-23.

8. Embaby AS (2014) Histological and immunohistochemical study on the possible protective effect of curcumin on intestinal ischemia/reperfusion induced lung injury in albino rats. Egyptian J Histol 37: 16-23.

9. El-Haroun H (2016) Microscopic study of a possible ameliorating role of curcumin against the effects of first-generation and second-generation antipsychotic drugs in adult rat cerebral cortex. Egyptian J Histol 39: 96-108.

10. Sadek EM, Afifi NM, AbdElfattah LA, Abd-El Mohsen MA (2013) Histological study on effect of mesenchymal stem cell therapy on experimental renal injury induced by ischemia/reperfusion in male albino rat. Int J Stem Cells 6: 55-66. [PubMed]

11. Salem MY, El-Azab NE, Helal OK, Metwaly HG, Bayoumi HE (2015) Does selenium improve the stem cell therapeutic effect on isoproterenol-induced myocardial infarction in rats? a histological and immunohistochemical study. Egyptian J Histol 38: 679-691.

12. Eldrieny EA, Sarhan NI, Laag EM, Badr SM (2014) Histological study of the effect of bone marrow-derived mesenchymal stem cells on healing of skin defect in adult male albino rats. Egyptian J Histol 37: 186-196.

13. Mohammed SA, Moussa MH, Shaker SM, Ahmed SA (2014) The effect of bone marrow-derived mesenchymal stem cells on the healing of experimental skin wound in diabetic adult malealbino rats. Egyptian J Histol 37: 360-372.

14. Salem MY, El-Azab NE-E, Faruk EM (2014) Modulatory effects of green tea and aloe vera extracts on experimentally-induced lung fibrosis in rats: histological and immunohistochemical study. J Histol Histopathol 1: 1-7.

15. Lan YW, Choo KB, Chen CM, Hung TH, Chen YB, et al. (2015) Hypoxiapreconditioned mesenchymal stem cells attenuate bleomycin-induced pulmonary fibrosis. Stem Cell Res Ther 6: 1-17. [PubMed]

16. El-Mahalaway AM (2015) Protective effect of curcumin against experimentally induced aflatoxicosis on the renal cortex of adult male albino rats: a histological and immunohisochemical study. Int J Clin Exp Pathol 8: 6019-6030. [PubMed]

17. Soleimani M, Nadri S (2009) A protocol for isolation and culture of mesenchymal stem cells from mouse bone marrow. Nat Protoc 4: 102-106. [PubMed]

18. Ahmed SK, Mohammed SA, Khalaf G, Fikry H (2014) Role of bone marrow mesenchymal stem cells in the treatment of CCL4 induced liver fibrosis in albino rats: A Histological and Immunohistochemical Study. Int J Stem Cells 7: 87-97. [PubMed]

19. Bancroft JD, Layton C (2013) The hematoxylin and eosin, connective and mesenchymal tissues with their stains. In: Suvarna SK, Layton C, Bancroft JD (eds). Bancroft's Theory and practice of histological techniques $\left(7^{\text {th }}\right.$ edn). Churchill Livingstone, Philadelphia, pp: 173-212.

20. Ma W, Quirion R (2005) Up-regulation of interleukin-6 induced by prostaglandin $E$ from invading macrophages following nerve injury: an in vivo and in vitro study. J Neurochem 93: 664-673. [PubMed]

21. Valenzuela A (1991) The biological significance of malondialdehvde determination in the assessment of tissue oxidative stress. Life Sci 48: $301-$ 309. [PubMed] 
Citation: MAltaib Z, EMansy A, EIMahlawy AM, Sabry D (2017) The Possible Ameliorative Effect of Mesenchymal Stem Cells and Curcumin Onbleomycin Induced Lung Injuries in the Adult Male Rats: Histological and Immunohistochemical Study. J Stem Cell Res Ther 7: 389 . doi: 10.4172/2157-7633.1000389

Page 13 of 13

22. Grifith OW (1980) Determination of glutathione and glutathione disulphide using glutathione reductase and 2-vinylpyridine. Anal Biochem 106: 207-212. [PubMed]

23. Corti A, Fassina G, Marcucci F, Barbanti E, Cassani G (1992) Oligomerictumour necrosis factor alpha slowly converts into inactive forms at bioactive levels. Biochem J 284: 905-910. [PubMed]

24. Emsley R, Dunn G, White IR (2010) Mediation and moderation of treatment effects in randomized controlled trials of complex interventions. Stat Methods Med Res 19: 237-270. [PubMed]

25. Yi-zhong F, Yong-sheng Z, Zhi-fei C, Zhen-lun G, Qing-yaoY, et al. (2010) Prevention of bleomycin-induced pulmonary fibrosis in mice by the combination of hirsutellasinensis and panaxnotoginseng extracts. Chinese Herbal Med 2: 118-124.

26. Hemmati AA, Rezaie A, Darabpour (2013) Preventive effects of promegranate seed extract on bleomyin-Induced pulmonary fibrosis in rat. Jundishapur J Nat Pharm Prod 8: 76-80. [PubMed]

27. Zhang Z, Yu X, Fang X, Liang A, Yu Z, et al. (2015) Preventive effects of vitamin D treatment on bleomycin-induced pulmonary fibrosis. Sci Rep 5: 17638. [PubMed]

28. Ribeiro EL, Barbosa KP, Fragoso IT, Donato MA, Santos Gomes FO, et al. (2014) Diethylcarbamazine attenuates the development of carrageenaninduced lung injury in mice. Hindawi Publishing Corporation Mediators of Inflammation 2014: 1- 12

29. Sabry MM, Elkalawy SA, Abo-Elnour RK, El-Maksod DF (2014) Histological and immunohistochemical study on the effect of stem cell therapy on bleomycin induced pulmonary fibrosis in albino rat. Int J Stem Cells 7: 33-42. [PubMed]

30. El-Mahalaway AM, Selim AA, Mahboub FA (2015) The potential protective effect of propolis on experimentally induced hepatitis in adult male albino rats. Histological and immunohistochemical study. J Histol Histopathol 2: 1-9.

31. Mansour MA, Seleem HS (2012) Evaluation of the beneficial efficacy of curcumin on experimental lung fibrosis of adult male albino rats: a light and electron microscopic study. Egyptian J Histol 35: 95-105.

32. Zaghloul DAM, Kamel ES, Abd el-Aziz HO, Mahmoud MA (2012) The possible protective role of curcumin on the toxic effect of nicotine in the lung of adult male mice: histological study. Egyptian J Histol 35: 805-811.

33. Zaglool SS, Zickri MB, Abd El Aziz DH, Mabrouk D, Metwally HG (2011) Effect of stem cell therapy on amiodarone induced fibrosing interstitial lung disease in albino rat. Int J Stem Cells 4: 133-142. [PubMed]

34. El-Attar S, Elsayed LA, Rashed L (2012) Role of stem cells and antioxidant on modulation of body defense mechanism in lipopolysaccharide-induced acute lung injury in rats. Med J Cairo Univ 80: 559-573.

35. Zhou C, Zou J, Zou S, Li X (2016) INO80 is Required for osteogenic differentiation of human mesenchymal stem cells. Sci Rep 6: 35924. [PubMed]

36. Campo F, Riancho J (2015) Epigenetic Mechanisms Regulating Mesenchyma Stem Cell Differentiation. Current Genomics 6: 368-383. [PubMed]

37. Yang J, Kaur K, Ong L, Eisenberg C, Eisenberg L (2015) Inhibition of G9a histone methyltransferase converts bone marrow mesenchymal stem cells to cardiac competent progenitor. Stem Cells Int 2015: 1-12. [PubMed]

38. Zhang R, Shao J, Xiang L (2011) GADD45A protein plays an essential role in active DNA demethylation during terminal osteogenic differentiation of adiposederived mesenchymal stem cells. J Biol Chem 47: 41083-41094. [PubMed]

39. Zhang T, Termanis A, zkan B, Rappsilber J, Ramsahoye B, et al. (2016) G9a/ GLP complex maintains imprinted DNA methylation in embryonic stem cells. Cell Rep 15: 77-85. [PubMed]

40. Ormond DR, Shannon C, Oppenheim J, Zeman R, Das K (2014) Stem cel therapy and curcumin synergistically enhance recovery from spinal cord injury. PLoS ONE 9: e88916. [PubMed]

41. Luan Y, Zhang L, Chao S, Liu X, Li K, et al. (2016) Mesenchymal stem cells in combination with erythropoietin repair hyperoxia-induced alveoli dysplasia injury in neonatal mice via inhibition of TGF- $\beta 1$ signaling. Oncotarget 7: 4708247094. [PubMed] 